\title{
Novel gene expression responses in the ovine abomasal mucosa to infection with the gastric nematode Teladorsagia circumcincta
}

\author{
Pamela A Knight ${ }^{1 *}$, Susan E Griffith ${ }^{1}$, Alan D Pemberton ${ }^{1}$, Judith M Pate ${ }^{1}$, Lauren Guarneri ${ }^{1}$, Katherine Anderson $^{1}$, \\ Richard T Talbot', Sarah Smith', David Waddington', Mark Fell', Alan L Archibald', Stewart TG Burgess², \\ David W Smith², Hugh RP Miller ${ }^{1}$ and Ivan W Morrison ${ }^{1}$
}

\begin{abstract}
Infection of sheep with the gastric nematode Teladorsagia circumcincta results in distinct Th2-type changes in the mucosa, including mucous neck cell and mast cell hyperplasia, eosinophilia, recruitment of IgA/lgE producing cells and neutrophils, altered T-cell subsets and mucosal hypertrophy. To address the protective mechanisms generated in animals on previous exposure to this parasite, gene expression profiling was carried out using samples of abomasal mucosa collected pre- and post- challenge from animals of differing immune status, using an experimental model of $T$. circumcincta infection. Recently developed ovine cDNA arrays were used to compare the abomasal responses of sheep immunised by trickle infection with worm-naïve sheep, following a single oral challenge of 50000 T. circumcincta L3. Key changes were validated using qRT-PCR techniques. Immune animals demonstrated highly significant increases in levels of transcripts normally associated with cytotoxicity such as granulysin and granzymes A, B and $\mathrm{H}$, as well as mucous-cell derived transcripts, predominantly calcium-activated chloride channel 1 (CLCA1). Challenge infection also induced up-regulation of transcripts potentially involved in initiating or modulating the immune response, such as heat shock proteins, complement factors and the chemokine CCL2. In contrast, there was marked infection-associated down-regulation of gene expression of members of the gastric lysozyme family. The changes in gene expression levels described here may reflect roles in direct anti-parasitic effects, immuno-modulation or tissue repair. (Funding; DEFRA/SHEFC (VT0102) and the BBSRC (BB/E01867X/1)).
\end{abstract}

\section{Introduction}

Parasitic gastroenteritis (PGE), caused by trichostrongylid nematodes, is the most commonly diagnosed systemic disease of sheep in the U.K. The principal causative nematode is the abomasal parasite Teladorsagia circumcincta. Control currently depends on the use of anthelmintics, but is failing due to the rapid emergence of drug resistance in the target nematodes [1]. Immunity builds up slowly on repeated exposure to the parasite, indicating vaccination could be a feasible alternative, but vaccine development is hampered by a lack of knowledge of the host-parasite interaction to infective

\footnotetext{
* Correspondence: pamaknight@gmail.com

'The Roslin Institute and R(D)SVS, University of Edinburgh, Roslin, Midlothian, EH25 9RG, Scotland, UK

Full list of author information is available at the end of the article
}

larvae. This immunity can be replicated experimentally by giving animals a low level trickle infection over several weeks, which results in a significant level of protective immunity to $T$. circumcincta challenge, measurable by reduced worm burdens, stunting of the worms and increased levels of larval arrest [2-4]. Protective immunity includes both cellular and humoral components; previously exposed animals undergo a local blast cell response in the draining lymphatics which can convey protection to genetically identical naïve recipients $[2,5]$, while local IgA/IgE responses have been associated with certain protective responses such as stunted growth and reduced fecundity of the worms $[4,6,7]$. T. circumcincta challenge in previously immunised sheep elicits local predominantly Th2 cytokine expression, compared to a more Th1-bias in naïve animals $[8,9]$. This response is
C Biomed Central

(C) 2011 Knight et al; licensee BioMed Central Ltd. This is an Open Access article distributed under the terms of the Creative Commons Attribution License (http://creativecommons.org/licenses/by/2.0), which permits unrestricted use, distribution, and reproduction in any medium, provided the original work is properly cited. 
accompanied by distinct Th2-type changes in the mucosa, such as mucous neck cell and mast cell hyperplasia, eosinophilia, recruitment of IgA/IgE producing cells and neutrophils, altered T-cell subsets and mucosal hypertrophy [10-14]. However, the molecular changes involved, and the relative contributions of these factors to both control of infection and the clinical symptoms of disease, are still poorly understood. The host immune responses may act concordantly to generate an unfavourable micro-environment [15], which could involve generation of specific antibodies to reduce worm fecundity or feeding [6,7], or promote rapid expulsion [16]. To identify the molecular changes generated in the abomasal mucosa in animals after previous exposure to this parasite, gene expression profiling was carried out using ovine cDNA microarrays on samples of abomasal mucosa collected pre- and post-challenge from animals of differing immune status. The significance of the key changes observed is discussed.

\section{Materials and Methods}

All experimental research described in this manuscript was carried out in accordance with Moredun Research Institute, Roslin Institute and R(D)SVS guidelines. All experimental protocols were approved by the Moredun Research Institute Experiments and Ethical Review Committee and authorised under the UK Animals (Scientific Procedures) Act 1986.

\section{Infections and sample collection}

A series of experimental trials were set up to compare the immune responses of "previously infected" yearling sheep immunised by an eight-week trickle infection (referred to subsequently as "immune" throughout this manuscript), with worm-free naïve yearling sheep, at different timepoints post-challenge with a single dose of 50 $000 \mathrm{~T}$. circumcincta L3. The details of these infection trials are summarised in Table 1 . All sheep were housed under worm-free conditions. Previously described work has established that there were significant differences in anti-parasite responses between the "naïve" and "immune" groups used in this study [4,11]. Samples of host material collected post-mortem included abomasal fold (anterior to the fundic region) for RNA extraction [17]. RNA was extracted as described previously [17] and assessed for quality and quantity using an Agilent 2100 Bioanalyzer (Agilent Technologies UK Ltd, Edinburgh, U.K.) according to ARK-Genomics standard protocols [18].

\section{Hybridisations and statistical analysis}

Ovine cDNA microarrays (ARK-Genomics O. aries $12 \mathrm{~K}$ v1.0) were generated at ARK-Genomics using PCRamplified products from individual cDNA clones predominantly from the KN511 library; a normalised cDNA library generated from gastrointestinal tract and lymphoid tissues of worm-free and T. circumcincta infected sheep, supplemented with an existing sheep/brain library [19]. Expressed Sequence Tags (ESTs) for each cDNA clone have been deposited in the EMBL/Genbank public DNA sequence databases. The array was annotated on the basis of homologous bovine sequences using Unigene, DfCI Gene Index, Ensembl cDNA library and the International Protein Index.

In order to characterise responses at day 5 (Expt.1) and day 0/day 2 (Expt. 2) post-challenge (Table 1), RNA samples were fluorescently labelled and competitively hybridised to the ovine cDNA microarrays using ARKGenomics standard protocols [18]. Samples were paired in a dye-balanced arrangement as indicated in Table 2 . The groups of samples being paired will be termed throughout this manuscript as $\mathrm{Nvd} 5 / \mathrm{Nvd0}$ (i.e. naive day 5 post-challenge vs. day 0 (unchallenged)), Imd5/ Nvd5 (i.e. immune vs. naive day 5 post-challenge), Imd0/Nvd0 (i.e. immune vs. naive day 0 (unchallenged)) and $\mathrm{Nvd} 2 / \mathrm{Nvd} 0$ or Imd2/Imd0 (i.e. naive or immune

Table 1 Design of $T$. circumcincta infection trials in yearling sheep

\begin{tabular}{|c|c|c|c|c|c|c|c|c|}
\hline \multirow[t]{2}{*}{ Trial } & \multirow[t]{2}{*}{ Group } & \multicolumn{2}{|l|}{ Treatment } & \multicolumn{5}{|c|}{ Days post-challenge $^{a} ;$ no. of sheep } \\
\hline & & Trickle inf ${ }^{\mathbf{b}}$ & clearance $^{c}$ & $0^{d}$ & 2 & 5 & 10 & 21 \\
\hline \multirow[t]{2}{*}{ Expt. 1} & Naïve (Nv) & - & + & 6 & - & 6 & 6 & 6 \\
\hline & Immune $(I \mathrm{~m})^{\mathrm{e}}$ & + & + & - & - & 6 & 6 & - \\
\hline \multirow[t]{2}{*}{ Expt. 2} & Naïve (Nv) & - & + & 6 & 6 & - & - & - \\
\hline & Immune $(I \mathrm{~m})^{\mathrm{e}}$ & + & + & 6 & 6 & - & - & - \\
\hline
\end{tabular}

The experimental model of infection used in this study is summarised. Details are given in the footnotes. Two experimental trials were carried out; Expt.1; addressing differences between immune ("previously infected") and naïve sheep at days 5 and 10 post challenge, and Expt.2, addressing differences between immune and naïve and sheep without challenge (day 0 ) and early post-challenge (day 2).

${ }^{\mathrm{a}} 1 \times 50000$ T. circumcincta L3 on Day 0

${ }^{\text {b } 2000 ~ T . ~ c i r c u m c i n c t a ~ L 3 ~} 3 \times$ per wk for eight weeks

'Levamisole $(7.5 \mathrm{mg} / \mathrm{kg}) 7$ days before challenge

${ }^{\mathrm{d}}$ Day $0=$ unchallenged

epreviously infected by trickle infection 
Table 2 Hybridisation design

\begin{tabular}{llll}
\hline Experiment & \multicolumn{3}{l}{ Hybridisations $(\mathbf{d}=$ days post-challenge $)$} \\
\hline Expt. $\mathbf{N}$ & $\mathrm{Nvd} / \mathrm{Nvd5}$ & $\mathrm{Nvd5} / \mathrm{Imd} 5$ & \\
Day $\mathbf{5}$ post-challenge & $(n=6)$ & $(n=6)$ & \\
\hline Expt. $\mathbf{2}$ & $\mathrm{Nvd} 2 / \mathrm{Nvd0}$ & $\mathrm{Imd} / \mathrm{Nvd0}$ & $\mathrm{Imd} / \mathrm{Imd} 0$ \\
Day $\mathbf{2}$ post-challenge & $\left(n=5^{\mathrm{a}}\right)$ & $\left(n=5^{\mathrm{a}}\right)$ & $\left(n=5^{\mathrm{a}}\right)$ \\
\hline
\end{tabular}

Samples in both cDNA hybridisation experiments were paired as indicated with a dye-balanced arrangement (three cy $3 /$ cy $5 \&$ three cy $5 /$ cy 3 hybridisations). Nv = "naïve" yearlings, worm naïve prior to challenge; $\mathrm{Im}$ = "immune" yearlings, previously infected by trickle infection prior to challenge (see Table 1). Common samples linked the sets of paired hybridisations (Expt 1: Nvd5 samples, Expt. 2: Nvd0 \& Imd0 samples). An indirect comparison between the results from all three hybridisations gave the (Nvd2/Nvd0)/(Imd2/Imd0) gene list. ${ }^{a}$ One chip failed hybridisation QC in Expt 2 and so was removed from the analysis, along with chips linked to it.

day 2 post-challenge vs. day 0 (unchallenged)), and as shown in Table 2. Scanning and data capture using Bluefuse feature extraction software (BlueGnome Limited, Cambridge, United Kingdom) was undertaken according to ARK-Genomics standard protocols [18]. $\log _{2}$ (intensity ratios) were subjected to spatial and intensity dependent normalisations to remove technical bias by spatial row and column averaging [20] and M-A lowess correction [21]. Means of normalized gene $\log _{2}$ (intensity ratios) were compared for treatment effects and treatment-by-dye interactions by ANOVA followed by $t$-tests, using modifications of the Limma package [22]. Statistical analysis to generate gene lists was based on each sample coming from a different sheep, and fitting the two (Expt. 1) or three (Expt. 2) dye-balanced arrangements with a common error variance. T-tests were modified by the Limma eBayes correction [23]. Genes with Benjamini \& Hochberg false discovery rate $\leq$ 0.05 [24] were considered to show significantly different expression levels. Normalisations and analyses were weighted by the Bluefuse "confidence" measure [25]. Subsets of the data from Expt. 2; genes whose expression levels were significantly changed $($ FDR $\leq 0.05) \geq 1.5$ fold from the Imd $0 / \mathrm{Nvd0}$ and Imd $2 /$ Imd 0 gene lists (Table 1)); were analyzed through the use of Ingenuity Pathways Analysis (Ingenuity ${ }^{\circledR}$ Systems (Redwood City, CA, U.S.A) [26]) by inputting human gene symbols (HUGO) for their putative ovine orthologues.

\section{RT-PCR and multiplex qRT-PCR analysis}

Subsequent validation assays for selected groups of genes whose expression levels were significantly changed $($ FDR $\leq 0.05) \geq 2$ fold were carried out initially by semiquantitative RT-PCR and sequence analysis of products to confirm identity. Methods for reverse transcription, polymerase chain reaction and purification of PCR products have been described previously [17,27]. Gene-specific primers were designed from the ovine sequences (ESTs) for the relevant KN511 cDNA clones, or previously published sequences, using the Primer 3 program; [28]. Primers and PCR conditions for RT-PCR are shown in Additional file 1: Table S1. Three "housekeeping" genes found to show no significant change in any of the array analyses (ATPase, RW1 and TM57; Table 3) were used as positive controls. Sequence analysis of PCR products was carried out using multiple alignment and sequence similarity search programs available on $[29,30]$ and [31].

In order to provide quantitative data on gene expression for the transcripts investigated above, two multiplex competitive qRT-PCR assays were designed from published sequences as summarised in Table 3; which included a total of 21 study genes and 3 "housekeeping" genes. Multiplex competitive qRT-PCR assays were designed by Sequenom Inc. (San Diego, CA, USA) using QGE assay designer software, version 3.4 (Sequenom ${ }^{\circledR}$ MassARRAY ${ }^{\circledR}$ System; [32]. These assays were used to compare levels of transcripts for each gene in naïve sheep with immune sheep at days $0,2,5$ and 10 and 21 post-challenge, by running the multiplex qRT-PCR assays with cDNA from all 60 RNA samples summarised in Table 1. The assays and data collection were carried out using Sequenom standard protocols for quantitative gene expression [33]. Significant differences were identified using the Mann-Whitney U-test for nonparametric data.

\section{Results}

\section{Results of microarray analysis}

The numbers of transcripts that exhibited significant changes in expression levels (Benjamini \& Hochberg FDR $\leq 0.05$ ) in Expts. 1 and 2 are summarised in the Venn diagrams in Figure 1, and in Additional file 1 Table S2. In both experiments, the highest numbers of transcripts showing significantly altered expression levels (approx $>2 \mathrm{~K}$ ) were associated with the challenged immune group (day 2 or day 5 ) compared to day 0 of the same group, or compared to naive animals at the same timepoint post-challenge (Figure 1a and 1b). There were no significantly differentially expressed genes in the $\mathrm{Nvd} 2 / \mathrm{Nvd0}$ comparison from Expt. 2. Any transcripts showing significant $(F D R \leq 0.05)$ treatmentby-dye interactions (Additional file 1: Table S2; Expt. 2) were removed from the gene lists. This precautionary measure excluded pairs of treatment estimates (from cy5-cy3 or cy3-cy5 dye orientations) with conflicting signs and some pairs of treatment estimates with the largest proportionate differences in magnitude (graphs not presented). The complete gene lists of significantly differentially expressed genes, with significant treatment-by-dye interactions excluded, are available under Array Express [34] or by contacting the authors. Data from Expt. 2 were analysed through the use of 
Table 3 Details of gene sequences, and likely function, selected for further analysis

\begin{tabular}{|c|c|c|c|c|}
\hline Functional Category & Gene Name & Clone/probe ID on KN511 cDNA array & EMBL acc. no. & Assay \\
\hline \multirow[t]{5}{*}{ Cytotoxicity } & GNLY & C0009264H11.P1KAM13F & FE028690 & W1 \\
\hline & CatC & sh1-aoo11_10.s2 & DY479012 & W2 \\
\hline & GZMA & KN511_9486f02 & FE037399 & W2 \\
\hline & GZMB & KN511_9253n09 & FE021442 & W1 \\
\hline & GZMH & KN511_9260m05 & FE026184 & W2 \\
\hline \multirow[t]{4}{*}{ Mucus composition } & CLCA1 & 020502OAPP1012080HT OAPP & EE748540 & W1 \\
\hline & ITLN1 & $a^{a}$ & AM087961 & W2 \\
\hline & ITLN2 & KN511_9264a24.p1kaM13F & EF521881 & W2 \\
\hline & ITLN3 & $-{ }^{a}$ & AM888394 & W2 \\
\hline \multirow[t]{3}{*}{ Heat shock response } & HSPA8 & KN511_9479003 & DY491193 & W1 \\
\hline & HSPCA & KN511_9253c04 & FE020983 & W2 \\
\hline & ST1 & KN511_9486e08 & FE037366 & W1 \\
\hline \multirow[t]{3}{*}{ Proinflammatory response } & PLA2G2A & KN511_9482g22 & FE034658 & W1 \\
\hline & CF1 & KN511_9257m10 & FE024140 & W1 \\
\hline & CCL2 & KN511_9477e07 & FE031007 & W1 \\
\hline \multirow[t]{3}{*}{ Tissue remodelling } & MMP13 & KN511_9487m11.p1kM13F & AY091604 & W1 \\
\hline & MMP23 & sh1-bjd04_10.s2 & DY483383 & W2 \\
\hline & CST3 & KN511_9476g20 & FE030675 & W1 \\
\hline \multirow[t]{2}{*}{ Digestion } & LZM1A & KN511_9487n22.p1kM13F & M32492 & W1 \\
\hline & LZM4A & KN511_9487n22.p1kM13F ${ }^{\mathrm{b}}$ & M32497 & W1 \\
\hline Unknown & MALAT & KN511_9484l14 & FE036272 & W1 \\
\hline \multirow[t]{3}{*}{ "Housekeeping" genes } & ATPase & KN511_9488b23.p1kM13F & X02813 & W1/W2 \\
\hline & RW1 & KN511_9261h17 & FE026635 & W1/W2 \\
\hline & TM57 & KN511_9488i21 & FE030125 & W1/W2 \\
\hline
\end{tabular}

The EMBL accession no. for the sequences used to design multiplex competitive qRT-PCR assays (Sequenom ${ }^{\circledR}$ MassARRAY ${ }^{\circledR}$ System) is given, together with the representative probe on the ovine CDNA array. The two multiplex competitive qRT-PCR assays were designated W1 and W2 as indicated.

anly ITLN2 was represented on the arrays.

${ }^{\mathrm{b}}$ These CDNA probes would not be able to distinguish between LZM1A, $3 \mathrm{~A}$ and $4 \mathrm{~A}$.

a)

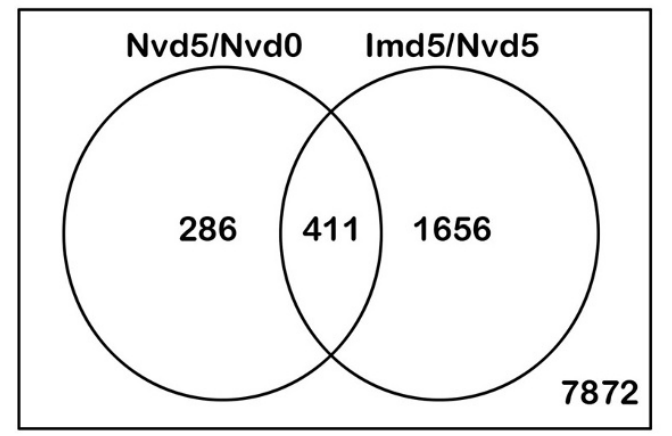

b)

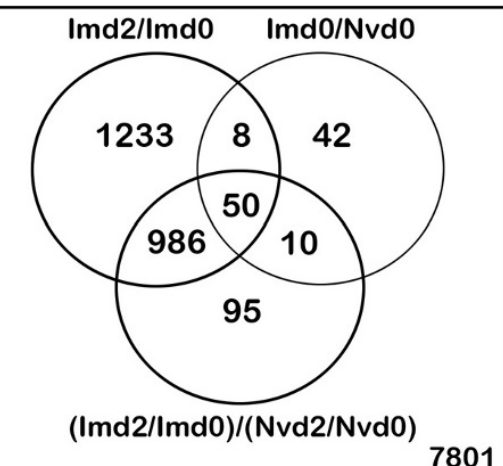

Figure 1 Venn diagrams to illustrate total numbers of genes whose expression levels were significantly altered (FDR $\leq 0.05)$ detected in each hybridisation experiment; 1a) Expt.1; day 5 post-challenge 1b) Expt. 2; day 2 post-challenge. Nv = "naïve" yearlings, worm naïve prior to challenge; Im = "immune" yearlings, previously infected by trickle infection prior to challenge; d0, d2, d5 = days post-challenge; (details in Table 1). The figures in the circled regions correspond to the number of genes with significantly altered (FDR $\leq 0.05)$ expression levels in each comparison (details given in Table 2) while the figures in the overlapping regions correspond to the number of genes whose expression levels were significantly altered (FDR $\leq 0.05)$ in two or more comparisons; eg. 8 genes showed significantly altered expression levels in both the Imd2/ Imd0 and Imd0/Nvd0 comparisons. The figures outside the circled regions correspond to the numbers of genes on the array with no significant change in expression level in any of the comparisons. 
Ingenuity Pathways Analysis (Ingenuity ${ }^{\circledR}$ Systems, [26]). Data were analysed from two datasets of genes whose expression levels were significantly changed (FDR $\leq$ 0.05 ) $\geq 1.5$ fold in Expt. 2 (see Table 2): Imd0/Nv d0; to highlight changes induced by trickle infection immunisation, and Imd2/Imd0; to highlight early $(<48 \mathrm{~h})$ changes induced following challenge of immunised animals. For each differentially expressed ovine transcript of interest the gene identifier (HUGO) for the putative orthologous human gene and the transcript's expression value were uploaded into the application. The output of the top 20 most significant (Fisher's exact test) biological functions are shown in Figure 2. Significant networks $\left(P \leq 10^{-10}\right.$; Fischer's exact test) identified from the Imd0/Nvd0 and Imd2/Imd0 datasets from Expt. 2 are shown in Additional file 2 Table S3. Pathways were identified from the Ingenuity Pathways Analysis (Ingenuity ${ }^{\mathbb{B}}$ Systems, [26]) library of canonical pathways that were most significant to the data set. The top 20 most significant canonical pathways from the Imd0/Nvd0 and
Imd2/Imd0 datasets from Expt. 2 are shown in Additional file 2 Table S4.

The biological function associated with the most significant changes (Figure 2) in the Imd0/Nvd0 comparison was "Cell Cycle", which also features as the most significant network (Additional file 2 Table S3) probably reflecting the increased cellular turnover occurring in the immune versus naïve abomasum. "Cancer" was the most significant function from the Imd2/Imd0 comparison, which is likely to relate to increased transcription factor activity following challenge of the immunised sheep. It is notable that the functions "Inflammatory Disease", Immunological Disease", "Infectious Disease" and "Cell-mediated Immune Response" were identified in the Imd2/Imd0 comparison only, which is indicative of increased innate and adaptive immune responses within $48 \mathrm{~h}$ following challenge. The most significant network from the Imd2/Imd0 comparison is "Hematological Disease, Small Molecule Biochemistry, Cellular Compromise" (Additional file 2 Table S3); further

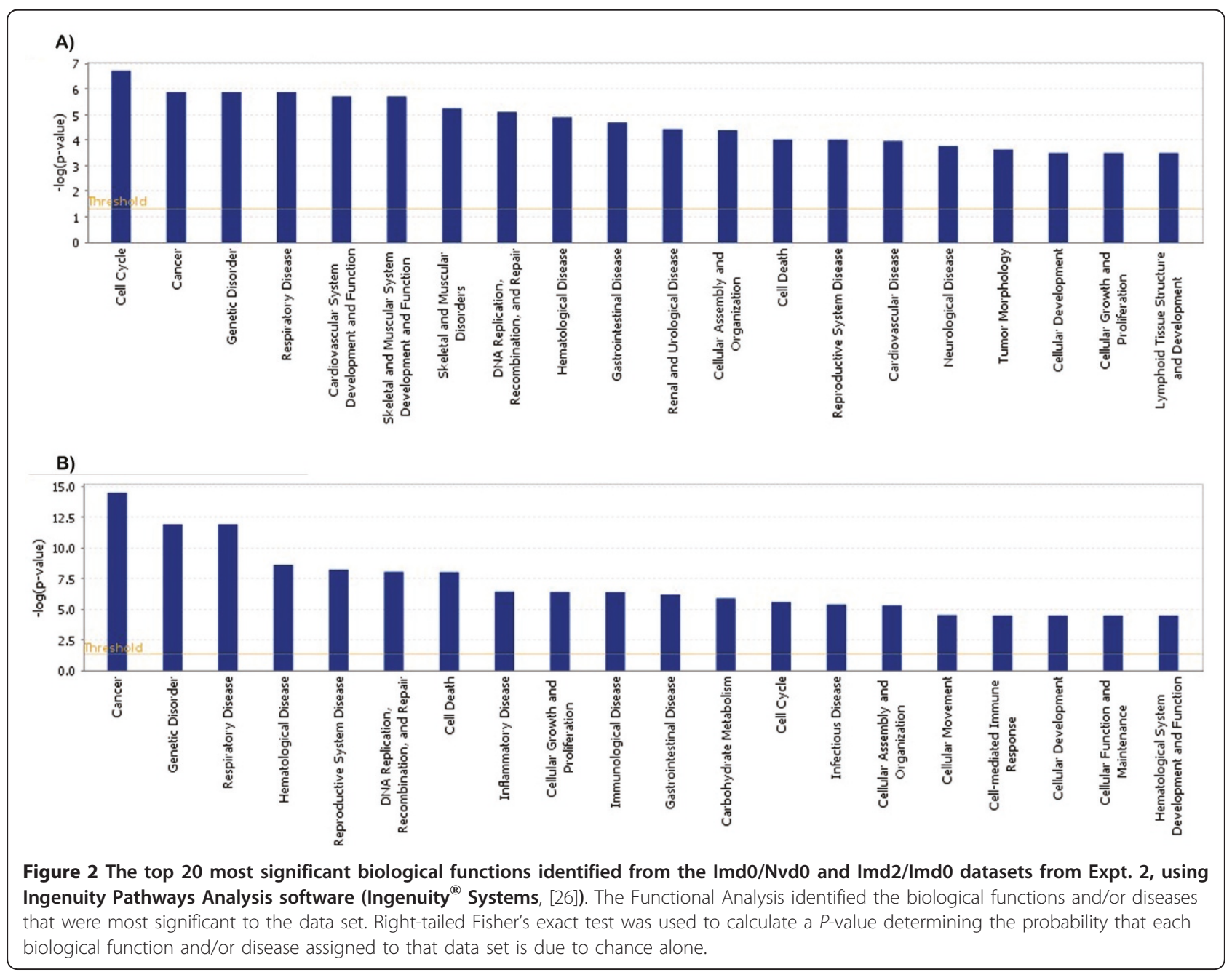


pathway analysis of this subset (data not shown) showed the most significant pathways within this network were the "Complement System", "Granzyme B signalling" (i.e. Granzyme B pathway), "Huntington's Disease signalling” and "NRF2-mediated oxidative stress response"; the latter two pathways predominantly involve heat shock proteins. It is notable that NFkB signalling predominated in many of the pathways within this network. The 20 most significant pathways from the whole Imd0/Nvd0 and Imd2/Imd0 datasets are shown in Additional file 2 Table S4.

The 20 most significantly (FDR $\leq 0.05$ ) up- and downregulated transcripts from both experiments are shown in Tables 4 (up-regulated transcripts) and 5 (down-regulated transcripts). Fold changes of a selection of these transcripts, grouped under possible function, are illustrated diagrammatically in Figure 3. Transcripts of particular biological interest, listed in Table 3, were selected for further investigation, initially by semi-quantitative RT-PCR (Additional file 1 Table S1) and sequence analysis to validate expression in the abomasum and sequence identity (data not shown) and subsequently, by multiplex competitive qRT-PCR analyses (Table 3). The aims of these assays were to validate the key findings from the array analysis (Figure 3), and to examine temporal changes in response to challenge infection in both the naïve and immune groups, using samples collected at post-mortem on days $0-21$ postchallenge as summarised in Table 1 . The results of the multiplex qRT-PCR analyses are shown in Figures 4, 5, 6 and 7. The results are discussed below in the context of transcripts specific to particular cell types and/or likely to share a similar function.

\section{Transcripts normally associated with cells exhibiting cytotoxicity}

Transcripts for granulysin were identified as the most highly up-regulated in immune sheep (+94 fold), compared with naïve at day 5 post-infection (p.i.) (Table 4; Figure 3 ), and were confirmed to show significantly $($ FDR $\leq 0.05)$ highly up-regulated expression in immune animals at all timepoints post-challenge by multiplex qRT-PCR (Figure 4). We also observed a $+2-5$ fold upregulation of transcripts for granzymes $\mathrm{A}, \mathrm{B}$ and $\mathrm{H}$ in immune animals on day 5 post-challenge compared with naïve, and a $>7$ fold up-regulation of cathepsin $C$ transcripts in immune animals on day 2 after challenge compared to naïve or to day 0 (Figure 3a). Results from the multiplex qRT-PCR analysis showed significantly higher numbers of transcripts for granzymes $\mathrm{A}$ and $\mathrm{H}$ in immune abomasal samples compared to naïve at day 5 post-challenge, with elevated levels persisting at day 10 , but expression of granzyme B was highly variable and not significant (Figure 4). Transcripts for cathepsin C were generally 10 -fold more abundant in challenged animals at days 5-21 compared to day 0, although there were no significant differences between the immune and naïve groups (Figure 4). The 20 most significant pathways identified from the Imd $2 /$ Imd0 comparison included "Crosstalk between Dendritic cells and NK cells", "Granzyme B Signalling" and "Leukocyte Extravasation Signalling", indicative of an increased cellmediated immune response (Additional file 2 Table S4).

\section{Mucous-cell associated transcripts}

The mucous-cell associated transcript calcium-activated chloride channel 1 (CLCA1) was one of the most upregulated transcripts seen in immune sheep in both experiments. CLCA1 was the second most up-regulated transcript in immune versus naïve sheep day 5 postchallenge (Expt. 1) and was also among the most upregulated transcripts in the immune versus naïve sheep at day 0 and day 2 post-challenge (Expt 2) (Table 4, Figure 3b)). Significant (FDR $\leq 0.05)$ up-regulation of CLCA1 transcripts in immune versus naïve sheep was confirmed in the multiplex qRT-PCR analysis (day 5 post-challenge, Figure 5) and there was a general upregulation of expression in response to challenge (i.e. compared to day 0$)$ in both groups, significant $(P \leq$ 0.01 ) in naïve animals on days $5-21$. We also observed significant up-regulation of transcripts for the mucous cell product trefoil factor 3 (TFF3) in immune animals compared to naïve (Table 4; Figure 3b)), while trefoil factor 2 (TFF2) was highly down-regulated (Table 5).

While members of the intelectin family, galactosebinding lectins expressed by mucous neck cells [27], did not feature in the lists of significantly up-regulated genes from the microarray analysis (only ITLN2 (KN511_9264a24.p1kaM13F) was represented on the array), specific assays for all three of these genes were included in the multiplex qRT-PCR analysis as a positive control, since ITLNs 1,2 and 3 have been shown to be up-regulated in abomasal mucosa in response to $T$. circumcincta [35]. There was a significant up regulation in response to challenge in the naïve group for all 3 intelectins, with earlier up-regulation of ITLN-3 than ITLN1 and -2 , although these assays did not show significant differences between naïve and immune sheep (Figure 5). We also observed infection-associated up-regulation of transcripts for two galectins, which belong to the C-type lectin family; galectin 1 (+1.5 fold), and galectin $4(+1.6$ fold).

\section{Mast -cell associated transcripts}

Significantly (FDR $\leq 0.05)$ up-regulated gene expression of the high affinity IgE receptor in immune animals was detected on day $2(+1.5$ fold $)$ and day $5(+1.8$ fold $)$ postchallenge, compared to the naïve group at the same 
Table 4 The 20 most up-regulated transcripts detected in Expts. 1 and 2 (FDR $\leq 0.05$ )

\begin{tabular}{|c|c|c|c|c|}
\hline Sequence.ID & TIGR_TC & TC. description & $\begin{array}{l}\text { Gene } \\
\text { symbol }\end{array}$ & $\begin{array}{l}\text { Fold } \\
\text { Change }\end{array}$ \\
\hline \multicolumn{5}{|c|}{ EXPT 1. Comparison = Nvd5/Nvd0 } \\
\hline KN511_9480n02.p1kaM13F & TC385850 & - & - & 5.44 \\
\hline C0009213B13 & - & - & - & 1.81 \\
\hline KN511_9261j08.p1kaM13F & - & - & - & 1.77 \\
\hline KN511_9255d18.p1kaM13F & TC307335 & laminin B1 & LAMB1 & 1.64 \\
\hline KN511_9486f02.p1kM13F & TC305120 & UP|GRAA_BOVIN (Q7YRZ7) Granzyme A precursor, complete & gzmA & 1.59 \\
\hline KN511_9488i01.p1kM13F & TC311345 & $\begin{array}{l}\text { homologue to UP|Q96IL1_HUMAN (Q96IL1) DIAPH1 protein (Fragment), partial } \\
(43 \%)\end{array}$ & LOC786565 & 1.55 \\
\hline KN511_9483h09.p1kM13F & TC302202 & UP|Q3T119_BOVIN (Q3T119) FCGRT protein, complete & FCGRT & 1.53 \\
\hline CN822687 & TC381381 & $\begin{array}{l}\text { similar to emb|X79547.1|MIECCOMP Equus caballus mitochondrial DNA complete } \\
\text { sequence, partial (4\%) }\end{array}$ & - & 1.52 \\
\hline KN511_9257n17.p1kaM13F & - & - & - & 1.52 \\
\hline KN511_9479d15.p1kaM13F & TC361081 & similar to UP|O97916_BOVIN (O97916) Reverse transcriptase-like, partial (43\%) & - & 1.51 \\
\hline KN511_9486m17.p1kM13F & TC303503 & $\begin{array}{l}\text { UP|C1QA_BOVIN (Q5E9E3) Complement C1q subcomponent subunit A precursor, } \\
\text { complete }\end{array}$ & C1QA & 1.50 \\
\hline KN511_9257113.p1kaM13F & - & - & - & 1.50 \\
\hline KN511_9479o01.p1kaM13F & TC355858 & $\begin{array}{l}\text { GB|AAI02065.1|74353831|BC102064 CCL5 protein }\{\text { Bos taurus }\} \text { (exp = -1; wgp = 0; cg } \\
=0) \text {, complete }\end{array}$ & CCL5 & 1.50 \\
\hline CN823601 & TC342786 & - & - & 1.50 \\
\hline KN511_9486d22.p1kM13F & TC337098 & UP|Q3SZV9_BOVIN (Q3SZV9) Heat shock 10kDa protein 1 (Chaperonin 10), complete & HSPE1 & 1.50 \\
\hline KN511_9477j24.p1kaM13F & TC301808 & $\begin{array}{l}\text { UP|Q3ZC91_BOVIN (Q3ZC91) Sphingomyelin phosphodiesterase, acid-like 3A, } \\
\text { complete }\end{array}$ & LOC781963 & 1.48 \\
\hline KN511_9485e22.p1kM13F & - & - & - & 1.48 \\
\hline KN511_9253n18.p1kaM13F & TC317864 & UP|Q3KZ51_SCHJA (Q3KZ51) SJCHGC03568 protein (Fragment), partial (6\%) & MGC139367 & 1.48 \\
\hline KN511_9265g17.p1kaM13F & TC319596 & $\begin{array}{l}\text { homologue to UP|TCEA3_HUMAN (O75764) Transcription elongation factor A } \\
\text { protein } 3 \text { (Transcription elongation factor S-II protein 3) (Transcription elongation } \\
\text { factor TFIIS.h), complete }\end{array}$ & MGC137536 & 1.48 \\
\hline KN511_9265b23.p1kaM13F & - & - & - & 1.48 \\
\hline \multicolumn{5}{|c|}{ EXPT 1 Comparison = Imd5/Nvd5 } \\
\hline KN511_9264h11.p1kaM13F & TC331976 & $\begin{array}{l}\text { homologue to UP|Q864L7_BOVIN (Q864L7) Granulysin/NK-lysin-like protein } \\
\text { (Fragment), complete }\end{array}$ & GNLY & 94.0 \\
\hline KN511_9257k12.p1kaM13F & - & - & - & 5.91 \\
\hline KN511_9263m23.p1kaM13F & TC306994 & similar to UP|Q9TUB5_PIG (Q9TUB5) Epithelial chloride channel protein, partial (95\%) & CLCA1 & 5.15 \\
\hline KN511_9253n09.p1kaM13F & TC328399 & similar to UP|Q67BC3_HUMAN (Q67BC3) Endogenous granzyme B, partial (90\%) & LOC508646 & 5.14 \\
\hline KN511_9265g07.p1kaM13F & TC351879 & - & LOC614719 & 4.70 \\
\hline KN511_9260m05.p1kaM13F & - & - & - & 4.64 \\
\hline KN511_9260b08.p1kaM13F & TC330838 & - & - & 4.27 \\
\hline CN823175 & - & - & - & 3.14 \\
\hline CN823115 & TC329726 & $\begin{array}{l}\text { homologue to GB|CAA44699.1|440|BTIGG1HCX anti-testosterone antibody }\{\text { Bos } \\
\text { taurus\} (exp = -1; wgp = 0; } c g=0) \text {, partial }(70 \%)\end{array}$ & IGHG1 & 2.72 \\
\hline KN511_9480o15.p1kaM13F & - & - & - & 2.66 \\
\hline KN511_9476e05.p1kaM13F & TC330547 & $\begin{array}{l}\text { similar to UP|NBR1_PONPY (Q5RC94) Next to BRCA1 gene } 1 \text { protein (Neighbor of } \\
\text { BRCA1 gene } 1 \text { protein), partial (23\%) }\end{array}$ & LOC515032 & 2.64 \\
\hline KN511_9486a03.p1kM13F & TC350940 & $\begin{array}{l}\text { similar to UP|CAD26_MOUSE (P59862) Cadherin-like protein } 26 \text { precursor, partial } \\
\text { (11\%) }\end{array}$ & LOC617096 & 2.47 \\
\hline CO202749 & TC366134 & $\begin{array}{l}\text { similar to UP|Q48MR5_PSE14 (Q48MR5) Uncharacterized protein family UPF0016, } \\
\text { partial (58\%) }\end{array}$ & - & 2.45 \\
\hline KN511_9486013.p1kM13F & TC322636 & $\begin{array}{l}\text { weakly similar to UP|Q9R0M7_MOUSE (Q9R0M7) Aldo-keto reductase AKR1C12, } \\
\text { partial (91\%) }\end{array}$ & LOC507734 & 2.42 \\
\hline CN824147 & - & - & - & 2.38 \\
\hline CN823337 & TC313767 & UP|Q2FLD4_METHJ (Q2FLD4) ABC transporter related, partial (6\%) & - & 2.37 \\
\hline CO203065 & TC321552 & - & - & 2.34 \\
\hline KN511_9487e05.p1kM13F & TC302266 & $\begin{array}{l}\text { GB|AAC67307.1|1930063|BTU92535 neuronal axonal membrane protein }\{\text { Bos taurus\} } \\
(\exp =-1 ; \text { wgp }=0 ; \mathrm{cg}=0) \text {, complete }\end{array}$ & BASP1 & 2.30 \\
\hline
\end{tabular}


Table 4 The 20 most up-regulated transcripts detected in Expts. 1 and 2 (FDR ? $\leq$ ? 0.05) (Continued)

\begin{tabular}{|c|c|c|c|c|}
\hline KN511_9261f23.p1kaM13F & - & - & - & 2.29 \\
\hline KN511_9478a01.p1kaM13F & TC347423 & $\begin{array}{l}\text { similar to UP|GRAH_HUMAN (P20718) Granzyme H precursor (Cytotoxic T- } \\
\text { lymphocyte proteinase) (Cathepsin G-like 2) (CTSGL2) (CCP-X) (Cytotoxic serine } \\
\text { protease C) (CSP-C), partial (93\%) }\end{array}$ & LOC617313 & 2.28 \\
\hline KN511_9486110.p1kM13F & TC315163 & $\begin{array}{l}\text { similar to GB|AAH12303.1|15126763|BC012303 PDZK1 interacting protein } 1 \text { Homo } \\
\text { sapiens\} (exp = -1; } w g p=0 ; c g=0) \text {, complete }\end{array}$ & PDZK1IP1 & 2.21 \\
\hline CN824077 & - & - & - & 2.21 \\
\hline CN824594 & TC359921 & $\begin{array}{l}\text { homologue to UP|Q4K9Y4_PSEF5 (Q4K9Y4) BNR/Asp-box repeat protein, partial } \\
\text { (41\%) }\end{array}$ & - & 2.14 \\
\hline KN511_9260m24.p1kaM13F & - & - & - & 2.13 \\
\hline \multicolumn{5}{|c|}{ EXPT 2 Comparison $=$ Imd0/Nvd0 } \\
\hline KN511_9484k05.p1kM13F & TC323139 & $\begin{array}{l}\text { similar to UP|Q4TA31_TETNG (Q4TA31) Chromosome undetermined SCAF7459, } \\
\text { whole genome shotgun sequence, partial (10\%) }\end{array}$ & - & 3.59 \\
\hline KN511_9263m23.p1kaM13F & TC306994 & similar to UP|Q9TUB5_PIG (Q9TUB5) Epithelial chloride channel protein, partial (95\%) & CLCA1 & 2.99 \\
\hline KN511_9484p11.p1kM13F & - & - & - & 2.08 \\
\hline KN511_9485e08.p1kM13F & TC312631 & - & - & 1.61 \\
\hline KN511_9478a06.p1kaM13F & TC312631 & - & - & 1.49 \\
\hline KN511_9481c23.p1kaM13F & TC314684 & - & - & 1.46 \\
\hline CN823114 & TC301217 & $\begin{array}{l}\text { homologue to UP|NDRG1_HUMAN (Q92597) Protein NDRG1 (N-myc downstream- } \\
\text { regulated gene } 1 \text { protein) (Differentiation-related gene } 1 \text { protein) (DRG-1) (Reducing } \\
\text { agents and tunicamycin-responsive protein) (RTP) (Nickel-specific induction protein } \\
\text { Cap43) (Rit42), partial (97\%) }\end{array}$ & NDRG1 & 1.37 \\
\hline KN511_9257n17.p1kaM13F & - & - & - & 1.35 \\
\hline CN823685 & TC315004 & $\begin{array}{l}\text { similar to UP|Q3TT48_MOUSE (Q3TT48) Adult male pituitary gland CDNA, RIKEN full- } \\
\text { length enriched library, clone:5330433L19 product:proprotein convertase subtilisin/ } \\
\text { kexin type 2, full insert sequence. (Fragment), partial (3\%) }\end{array}$ & LOC615685 & 1.33 \\
\hline \multirow[t]{2}{*}{ KN511_9476g20.p1kaM13F } & TC337413 & $\begin{array}{l}\text { UP|CYTC_BOVIN (P01035) Cystatin C precursor (Colostrum thiol proteinase inhibitor), } \\
\text { complete }\end{array}$ & CST3 & 1.31 \\
\hline & - & - & - & 1.30 \\
\hline KN511_9259b18.p1kaM13F & TC371167 & - & - & 1.29 \\
\hline KN511_9479a08.p1kaM13F & TC318244 & UP|CATA_BOVIN (P00432) Catalase, partial (5\%) & MGC128112 & 1.29 \\
\hline CN823587 & - & - & - & 1.27 \\
\hline CO202780 & TC357183 & UP|Q71V68_MOUSE (Q71V68) Ldb1a, complete & LOC526472 & 1.26 \\
\hline KN511_9262a18.p1kaM13F & TC308953 & $\begin{array}{l}\text { UP|Q3T013_BOVIN (Q3T013) BCL2/adenovirus E1B 19kDa interacting protein 3-like, } \\
\text { partial (84\%) }\end{array}$ & BNIP3L & 1.26 \\
\hline CO202648 & TC301621 & homologue to UP|Q9HB23_HUMAN (Q9HB23) Lysyl-tRNA synthetase, complete & MGC127504 & 1.25 \\
\hline KN511_9254i12.p1kaM13F & TC381609 & homologue to UP|Q963G4_PLAFA (Q963G4) MB2 (Fragment), partial (3\%) & LOC508133 & 1.25 \\
\hline KN511_9261e18.p1kaM13F & - & - & - & 1.24 \\
\hline \multicolumn{5}{|c|}{ EXPT 2 Comparison = Imd2/Imd0 } \\
\hline KN511_9481e19.p1kaM13F & TC318483 & - & LRIG1 & 10.2 \\
\hline KN511_9256h20.p1kaM13F & TC309152 & similar to UP|O97916_BOVIN (O97916) Reverse transcriptase-like, partial (19\%) & - & 10.0 \\
\hline KN511_9257i19.p1kaM13F & TC375873 & - & - & 9.71 \\
\hline KN511_9481f19.p1kaM13F & TC345827 & $\begin{array}{l}\text { homologue to GB|CAl1 1042.1|55859631|AL353665 match: proteins: Q92802 \{Homo } \\
\text { sapiens\} (exp = 0; } w g p=1 ; c g=0) \text {, partial }(35 \%)\end{array}$ & LOC541201 & 9.17 \\
\hline KN511_9480f18.p1kaM13F & - & - & - & 8.94 \\
\hline CN822322 & TC309241 & nucleolin [Bos taurus] & $\mathrm{NCL}$ & 8.03 \\
\hline KN511_9483a22.p1kM13F & TC316336 & UP|Q3ZCJ8_BOVIN (Q3ZCJ8) Cathepsin C, complete & CTSC & 7.52 \\
\hline KN511_9263m23.p1kaM13F & TC306994 & similar to UP|Q9TUB5_PIG (Q9TUB5) Epithelial chloride channel protein, partial (95\%) & CLCA1 & 7.33 \\
\hline KN511_9483113.p1kM13F & TC340529 & $\begin{array}{l}\text { homologue to UP|Q9BTX0_HUMAN (Q9BTX0) RNA binding motif protein 10, } \\
\text { isoform 2, partial (69\%) }\end{array}$ & RBM10 & 6.73 \\
\hline KN511_9488g12.p1kM13F & TC304325 & $\begin{array}{l}\text { similar to GB|CAJ18388.1|71059689|CT010180 \{Mus musculus\} (exp = -1; wgp =0; cg } \\
=0 \text { ), complete }\end{array}$ & MGC127625 & 6.46 \\
\hline KN511_9263i18.p1kaM13F & TC332274 & UP|Q7ZU59_BRARE (Q7ZU59) H2AV protein (Fragment), partial (87\%) & $\mathrm{H} 2 \mathrm{AFZ}$ & 6.45 \\
\hline KN511_9253j02.p1kaM13F & TC331773 & $\begin{array}{l}\text { homologue to UP|HSP76_PIG (Q04967) Heat shock } 70 \text { kDa protein } 6 \text { (Heat shock } 70 \\
\text { kDa protein B'), complete }\end{array}$ & HSPA6 & 6.11 \\
\hline
\end{tabular}


Table 4 The 20 most up-regulated transcripts detected in Expts. 1 and 2 (FDR ? $\leq$ ? 0.05) (Continued)

\begin{tabular}{|c|c|c|c|c|}
\hline KN511_9487k02.p1kM13F & TC385703 & $\begin{array}{l}\text { UPIVPS28_MOUSE (Q9D1C8) VPS28 protein homolog (Caspase-activated DNase } \\
\text { inhibitor that interacts with ASK1) (CIIA), complete }\end{array}$ & VPS28 & 5.97 \\
\hline KN511_9265g07.p1kaM13F & TC351879 & - & LOC614719 & 5.84 \\
\hline KN511_9476g04.p1kaM13F & TC371801 & $\begin{array}{l}\text { homologue to SP|O60506|HNRPQ_HUMAN Heterogeneous nuclear } \\
\text { ribonucleoprotein Q (hnRNP Q) (hnRNP-Q)(Synaptotagmin binding, cytoplasmic } \\
\text { RNA interacting protein) (Glycine-and tyrosine-rich RNA binding protein) (GRY-RBP) } \\
\text { (NS1-associatedprotein 1). \{Homo sapiens\} (exp =-1; wgp =-1; cg =-1), partial } \\
(51 \%)\end{array}$ & SYNCRIP & 5.58 \\
\hline KN511_9263f17.p1kaM13F & TC355165 & $\begin{array}{l}\text { similar to UP|Q9XSA0_SHEEP (Q9XSA0) Pulmonary surfactant-associated protein B } \\
\text { (Fragment), partial (16\%) }\end{array}$ & - & 4.64 \\
\hline KN511_9476p04.p1kaM13F & TC329988 & UP|Q5E973_BOVIN (Q5E973) Ribosomal protein L18, complete & RPL18 & 4.47 \\
\hline KN511_9480118.p1kaM13F & TC364833 & - & - & 4.38 \\
\hline KN511_9265h18.p1kaM13F & TC303880 & $\begin{array}{l}\text { homologue to UP|O35328_MOUSE (O35328) Proline-rich protein 9-1 (Fragment), } \\
\text { partial (6\%) }\end{array}$ & - & 4.18 \\
\hline KN511_9260b08.p1kaM13F & TC330838 & - & - & 4.15 \\
\hline
\end{tabular}

The experiment and the samples being compared are given as subheadings at the top of each section. Nv = "naïve" yearlings, worm naïve prior to challenge; Im $=$ "immune" yearlings, previously infected by trickle infection prior to challenge, $\mathrm{d}=$ days post-challenge. Details of the experimental trials and hybridisation design are given in Tables 1 and 2.

timepoints. Up-regulated expression of cathepsin C, another potential mast cell transcript, has already been mentioned in the previous section. SMCP-1 and tryptase, which are expressed by abomasal mucosal mast cells during nematode infection [36,37], did not feature on this array.

\section{Heat shock proteins}

Significant up-regulation of a number of transcripts for heat shock proteins was detected in both microarray experiments. Transcripts for the heat shock proteins HSP1A (HSP70 protein 1A) and HSPA6 (HSP 70 protein 6) feature among some of the most significantly (FDR $\leq$ 0.05) highly up-regulated transcripts detected in immune sheep, up-regulated $(+3-7$ fold) by day 2 postchallenge in this group in comparison to naive (Figure 3c) and Table 4). The STIP1 (HSP70/90 organising protein; HOP) and HSPA8 (HSP70 protein 8) genes also appear to show significantly up-regulated expression in immune animals compared to naïve $(+1.5-2$ fold) (Figure 3c) and Table 4). Transcripts for HSPCA (HSP90a) appear to show significantly (FDR $\leq 0.05)$ increased levels on day 2 post-challenge in immune animals, although the expression pattern varies across the different comparisons (Figure 3c) and Table 4). The most significant network identified in the Imd2/Imd0 comparison (Network 1;"Cellular Compromise"; Additional file 2 Table S3) links STIP1 with a number of heat shock proteins in the HSP70/90 family. Multiplex qRT-PCR analysis showed that transcripts for STIP1 were significantly $(P \leq 0.01-0.05)$ increased day 5-21 post-challenge in the naïve group, with a similar trend in immune sheep, although there were no immune day 0 animals within the same trial (Figure 6). Multiplex qRT-PCR analysis, however, did not support all the findings for $H S P A 8$ and $H S P C A$, although there was a significant $(P \leq 0.05)$ challenge-associated increase in levels of HSPA8 transcripts in the naive group by day 10 (Figure 6).

\section{Transcripts associated with pro-inflammatory responses}

The microarray analyses demonstrated significant (FDR $\leq 0.05$ ) up-regulation of a number of transcripts associated with eicosanoid metabolism. Transcripts for PLA2G2A, which liberates arachidonic acid from phospholipids, were significantly up-regulated in response to challenge $(+3$ fold $)$, and in immune animals compared to naïve at day 2 and day 5 post-challenge $(+1.5-2$ fold $)$ (Figure $3 \mathrm{~d}$ ). The multiplex qRT-PCR analysis showed significant $(P \leq 0.05)$ up-regulation of PLA2G2A transcripts at day 5 post-challenge, but did not show significant differences between the naive and immune groups (Figure 6). Transcripts for prostaglandin E synthase (CPGES), another member of this pathway, appear to be significantly $(F D R \leq 0.05)$ up-regulated $(+1.6$ fold $)$ in immune animals by day 2 post-challenge compared to naïve animals. "Arachidonic Acid Metabolism" features among the significant pathways from the Imd0/Nvd0 comparison (Additional file 2 Table S4).

Transcripts for the chemokine CCL2 (MCP-1) were significantly up-regulated $>2$ fold on day 2 post-challenge in immune sheep, compared to naïve or unchallenged sheep (Figure 3d). Multiplex qRT-PCR analysis showed that transcripts for CCL2 were significantly $(P \leq$ 0.01-0.05) increased day 10-21 post-challenge in the naïve group in Expt. 1, with a similar trend in the immune group, but did not show significant differences between the two groups (Figure 6). Transcripts for the chemokine CCL5 (RANTES) were among the most upregulated in naïve sheep on day 5 post-challenge $(+1.5$ 
Table 5 The 20 most down-regulated transcripts detected in Expts 1 and 2 (FDR $\leq 0.05$ )

\begin{tabular}{|c|c|c|c|c|}
\hline Sequence.ID & TIGR_TC & TC.description & $\begin{array}{l}\text { Gene } \\
\text { symbol }\end{array}$ & $\begin{array}{l}\text { Fold } \\
\text { Change }\end{array}$ \\
\hline \multicolumn{5}{|c|}{ EXPT 1 Comparison $=\mathrm{d} 5 \mathrm{Nv} \_\mathrm{d} 0 \mathrm{Nv}$} \\
\hline KN511_9487m11.p1kM13F & TC336019 & $\begin{array}{l}\text { UP|MMP13_BOVIN (O77656) Collagenase } 3 \text { precursor (Matrix metalloproteinase-13) } \\
\text { (MMP-13), complete }\end{array}$ & MMP13 & -2.68 \\
\hline KN511_9481c03.p1kaM13F & TC304583 & $\begin{array}{l}\text { UP|LYSC1_BOVIN (Q06285) Lysozyme C-1 precursor (1,4-beta-N-acetylmuramidase } \\
\text { C), complete }\end{array}$ & LYZ2 & -2.37 \\
\hline KN511_9476d13.p1kaM13F & TC304583 & $\begin{array}{l}\text { UP|LYSC1_BOVIN (Q06285) Lysozyme C-1 precursor (1,4-beta-N-acetylmuramidase } \\
\text { C), complete }\end{array}$ & LYZ2 & -2.33 \\
\hline KN511_9485a08.p1kM13F & TC302650 & milk lysozyme [Bos taurus] & LYZ1 & -2.30 \\
\hline KN511_9485g08.p1kM13F & TC346615 & similar to UP|O97916_BOVIN (O97916) Reverse transcriptase-like, partial (32\%) & - & -2.23 \\
\hline KN511_9257d12.p1kaM13F & TC322737 & similar to UP|Q3VD89_9SPHN (Q3VD89) ABC-2, partial (5\%) & - & -2.16 \\
\hline KN511_9257a18.p1kaM13F & TC308928 & $\begin{array}{l}\text { similar to GB|AAK18773.1|13324523|F272846S31 Fanconi anemia complementation } \\
\text { group D2 protein, isoform } 2 \text { \{Homo sapiens\} (exp = -1; wgp = 0; } c g=0) \text {, partial } \\
\text { (18\%) }\end{array}$ & LOC515845 & -2.14 \\
\hline KN511_9262d01.p1kaM13F & - & - & - & -2.12 \\
\hline KN511_9261n23.p1kaM13F & TC362037 & $\begin{array}{l}\text { homologue to UP|IFRD1_PIG (Q5S1U6) Interferon-related developmental regulator } \\
\text { 1, complete }\end{array}$ & IFRD1 & -2.12 \\
\hline KN511_9476d14.p1kaM13F & TC349311 & $\begin{array}{l}\text { similar to UP|NEK4_HUMAN (P51957) Serine/threonine-protein kinase Nek4 (NimA- } \\
\text { related protein kinase 4) (Serine/threonine-protein kinase 2) (Serine/threonine- } \\
\text { protein kinase NRK2), partial (33\%) }\end{array}$ & MGC159441 & -2.08 \\
\hline KN511_9261 o08.p1kaM13F & TC305060 & homologue to UP|Q96BA7_HUMAN (Q96BA7) HNRPU protein, partial (93\%) & MGC142835 & -2.07 \\
\hline KN511_9258d23.p1kaM13F & - & - & - & -2.07 \\
\hline KN511_9487p21.q1kM13R & TC342358 & $\begin{array}{l}\text { homologue to UP|DC1L2_HUMAN (O43237) Cytoplasmic dynein } 1 \text { light } \\
\text { intermediate chain } 2 \text { (Dynein light intermediate chain 2, cytosolic) (LIC53/55) (LIC- } \\
\text { 2), complete }\end{array}$ & LOC519789 & -2.05 \\
\hline KN511_9262k18.p1kaM13F & TC375209 & $\begin{array}{l}\text { similar to UP|ZSWM3_HUMAN (Q96MP5) Zinc finger SWIM domain-containing } \\
\text { protein 3, partial (27\%) }\end{array}$ & LOC512244 & -2.05 \\
\hline KN511_9485d23.q1kM13R & TC365645 & $\begin{array}{l}\text { UP|LYSC2_BOVIN (Q06283) Lysozyme C-2 precursor (1,4-beta-N-acetylmuramidase } \\
\text { C), complete }\end{array}$ & LYZ2 & -2.04 \\
\hline KN511_9254g13.p1kaM13F & TC319944 & - & - & -2.02 \\
\hline KN511_9487h17.p1kM13F & TC327406 & UP|Q5DTN6_MOUSE (Q5DTN6) MKIAA4095 protein (Fragment), partial (8\%) & LOC614823 & -1.96 \\
\hline CO202908 & TC360504 & UP|Q3MHM4_BOVIN (Q3MHM4) Heat shock 70 kDa protein 8, complete & HSPA8 & -1.87 \\
\hline KN511_9482g13.p1kM13F & TC331274 & $\begin{array}{l}\text { homologue to UP|TENA_PIG (Q29116) Tenascin precursor (TN) (Hexabrachion) } \\
\text { (Cytotactin) (Neuronectin) (GMEM) (JI) (Miotendinous antigen) (Glioma-associated- } \\
\text { extracellular matrix antigen) (GP 150-225) (Tenascin-C) (TN-C) (P230), partial (10\%) }\end{array}$ & MGC140517 & -1.87 \\
\hline KN511_9482f05.p1kM13F & TC377013 & - & - & -1.86 \\
\hline \multicolumn{5}{|c|}{ EXPT 1 Comparison $=d 5 \mathrm{Im} \_d 5 \mathrm{Nv}$} \\
\hline KN511_9256g17.p1kaM13F & TC314535 & $\begin{array}{l}\text { homologue to UP|Q94513_DROME (Q94513) Boundary element associated factor } \\
\text { (LD44361p) (CG10159-PB, isoform B), partial (5\%) }\end{array}$ & - & -6.51 \\
\hline KN511_9256g17.p1kaM13F & TC314535 & $\begin{array}{l}\text { homologue to UP|Q94513_DROME (Q94513) Boundary element associated factor } \\
\text { (LD44361p) (CG10159-PB, isoform B), partial (5\%) }\end{array}$ & - & -5.97 \\
\hline KN511_9254|23.p1kaM13F & TC354719 & $\begin{array}{l}\text { similar to UP|TFF2_HUMAN (Q03403) Trefoil factor } 2 \text { precursor (Spasmolytic } \\
\text { polypeptide) (SP) (Spasmolysin), complete }\end{array}$ & MGC139191 & -5.54 \\
\hline KN511_9257115.p1kaM13F & TC354719 & $\begin{array}{l}\text { similar to UP|TFF2_HUMAN (Q03403) Trefoil factor } 2 \text { precursor (Spasmolytic } \\
\text { polypeptide) (SP) (Spasmolysin), complete }\end{array}$ & MGC139191 & -5.42 \\
\hline KN511_9260b10.p1kaM13F & TC365645 & $\begin{array}{l}\text { UP|LYSC2_BOVIN (Q06283) Lysozyme C-2 precursor (1,4-beta-N-acetylmuramidase } \\
\text { C), complete }\end{array}$ & LYZ2 & -3.92 \\
\hline KN511_9260m19.p1kaM13F & TC304583 & $\begin{array}{l}\text { UP|LYSC1_BOVIN (Q06285) Lysozyme C-1 precursor (1,4-beta-N-acetylmuramidase } \\
\text { C), complete }\end{array}$ & LYZ2 & -3.79 \\
\hline KN511_9483j03.p1kM13F & TC365645 & $\begin{array}{l}\text { UP|LYSC2_BOVIN (Q06283) Lysozyme C-2 precursor (1,4-beta-N-acetylmuramidase } \\
\text { C), complete }\end{array}$ & LYZ2 & -3.52 \\
\hline KN511_9265j02.p1kaM13F & CB220717 & - & - & -3.45 \\
\hline KN511_9264e04.p1kaM13F & TC314849 & UP|Q6SJV6_BOVIN (Q6SJV6) Foveolin precursor, complete & FOV & -3.33 \\
\hline KN511_9262k17.p1kaM13F & TC304583 & $\begin{array}{l}\text { UP|LYSC1_BOVIN (Q06285) Lysozyme C-1 precursor (1,4-beta-N-acetylmuramidase } \\
\text { C), complete }\end{array}$ & LYZ2 & -3.25 \\
\hline KN511_9476c18.p1kaM13F & TC365645 & $\begin{array}{l}\text { UP|LYSC2_BOVIN (Q06283) Lysozyme C-2 precursor (1,4-beta-N-acetylmuramidase } \\
\text { C), complete }\end{array}$ & LYZ2 & -3.25 \\
\hline
\end{tabular}




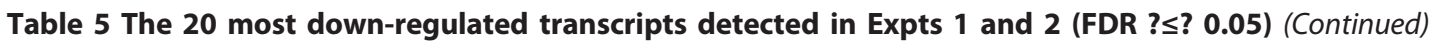

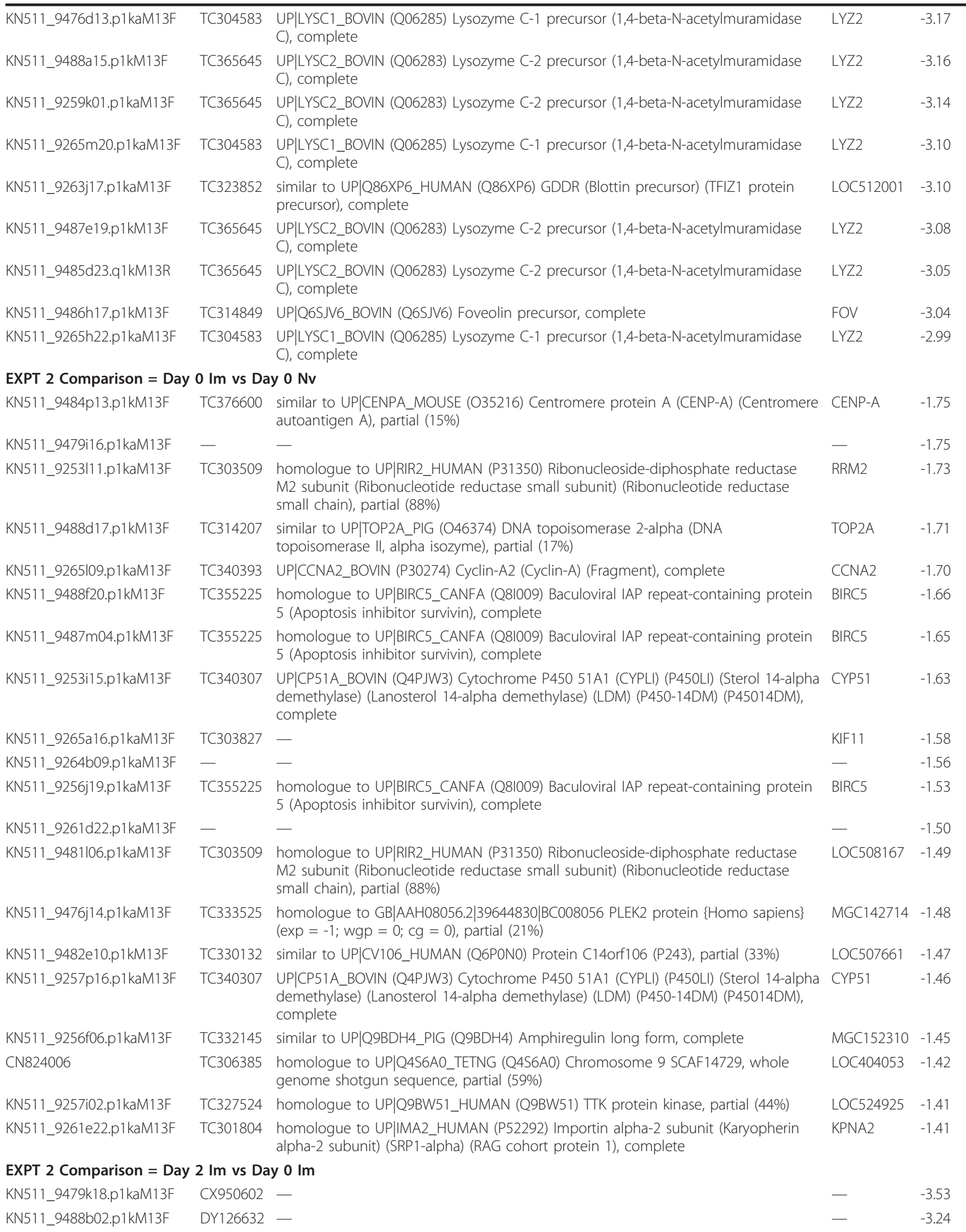


Table 5 The 20 most down-regulated transcripts detected in Expts 1 and 2 (FDR ? $\leq$ ? 0.05) (Continued)

\begin{tabular}{|c|c|c|c|c|}
\hline KN511_9257115.p1kaM13F & TC354719 & $\begin{array}{l}\text { similar to UP|TFF2_HUMAN (Q03403) Trefoil factor } 2 \text { precursor (Spasmolytic } \\
\text { polypeptide) (SP) (Spasmolysin), complete }\end{array}$ & TFF2 & -3.14 \\
\hline KN511_9254|23.p1kaM13F & TC354719 & $\begin{array}{l}\text { similar to UP|TFF2_HUMAN (Q03403) Trefoil factor } 2 \text { precursor (Spasmolytic } \\
\text { polypeptide) (SP) (Spasmolysin), complete }\end{array}$ & TFF2 & -3.03 \\
\hline KN511_9264e04.p1kaM13F & TC314849 & UP|Q6SJV6_BOVIN (Q6SJV6) Foveolin precursor, complete & FOV & -2.81 \\
\hline KN511_9263j17.p1kaM13F & TC323852 & $\begin{array}{l}\text { similar to UP|Q86XP6_HUMAN (Q86XP6) GDDR (Blottin precursor) (TFIZ1 protein } \\
\text { precursor), complete }\end{array}$ & GKN2 & -2.45 \\
\hline KN511_9486h17.p1kM13F & TC314849 & UP|Q6SJV6_BOVIN (Q6SJV6) Foveolin precursor, complete & FOV & -2.09 \\
\hline KN511_9261k22.p1kaM13F & TC327109 & similar to UP|O97916_BOVIN (O97916) Reverse transcriptase-like, partial (21\%) & - & -1.93 \\
\hline KN511_9486b13.p1kM13F & TC341767 & - & - & -1.90 \\
\hline KN511_9484h13.p1kM13F & TC350450 & $\begin{array}{l}\text { similar to UP|UDB5_MOUSE (P17717) UDP-glucuronosyltransferase 2B5 precursor } \\
\text { (UDPGT) (M-1), partial (49\%) }\end{array}$ & UGT2B17 & -1.81 \\
\hline KN511_9263c22.p1kaM13F & - & - & - & -1.80 \\
\hline KN511_9264a19.p1kaM13F & - & - & - & -1.77 \\
\hline KN511_9484l14.p1kM13F & TC362885 & $\begin{array}{l}\text { similar to UP|MALAT_HUMAN (Q9UHZ2) Metastasis-associated lung } \\
\text { adenocarcinoma transcript 1, partial (72\%) }\end{array}$ & MALAT1 & -1.75 \\
\hline KN511_9480l06.p1kaM13F & TC362885 & $\begin{array}{l}\text { similar to UP|MALAT_HUMAN (Q9UHZ2) Metastasis-associated lung } \\
\text { adenocarcinoma transcript 1, partial (72\%) }\end{array}$ & MALAT1 & -1.74 \\
\hline KN511_9481o23.p1kaM13F & TC350450 & $\begin{array}{l}\text { similar to UP|UDB5_MOUSE (P17717) UDP-glucuronosyltransferase 2B5 precursor } \\
\text { (UDPGT) (M-1), partial (49\%) }\end{array}$ & UGT2B17 & -1.73 \\
\hline CN824758 & - & - & - & -1.72 \\
\hline KN511_9488a17.p1kM13F & TC318925 & - & - & -1.71 \\
\hline KN511_9480o03.p1kaM13F & - & - & - & -1.70 \\
\hline KN511_9263o20.p1kaM13F & TC380127 & $\begin{array}{l}\text { similar to UP|UDB5_MOUSE (P17717) UDP-glucuronosyltransferase 2B5 precursor } \\
\text { (UDPGT) (M-1), partial (42\%) }\end{array}$ & UGT2B17 & -1.70 \\
\hline KN511_9484i14.p1kM13F & TC362885 & $\begin{array}{l}\text { similar to UP|MALAT_HUMAN (Q9UHZ2) Metastasis-associated lung } \\
\text { adenocarcinoma transcript 1, partial (72\%) }\end{array}$ & MALAT1 & -1.67 \\
\hline
\end{tabular}

The experiment and the samples being compared are given as subheadings at the top of each section. Nv = "naïve" yearlings, worm naïve prior to challenge; Im $=$ "immune" yearlings, previously infected by trickle infection prior to challenge, $d=$ days post-challenge. Details of the experimental trials and hybridisation design are given in Tables 1 and 2 .

fold; Figure 3d)), and were up-regulated in immune sheep compared to naive at this timepoint $(+1.4$ fold $)$.

Gene expression of several members of the complement cascade also appear to be up-regulated in response to $T$. circumcincta challenge. Complement factor 1 (CF1), and other members of the classical C1-complex, were significantly (FDR $\leq 0.05)$ up-regulated in immune sheep in response to challenge by day $2(+2-3$ fold), but not in naïve animals (Table 4 and Figure $3 d$ )). The "Complement System" was the third most significant pathway identified from the Imd $2 /$ Imd0 comparison (Figure 2), and the most significant pathway within the Network 1 subset from this comparison (Additional file 2 Table S3). However, the multiplex qRT-PCR analysis specific for complement factor 1 did not show the same pattern of expression detected in the arrays, with a lot of sheep-to-sheep variation, although there was a clear trend towards up-regulated gene expression in response to challenge in both groups in Expt. 1 (Figure 6).

\section{Matrix metalloproteinases and protease inhibitors}

Transcripts for the matrix metalloproteinase $M M P-23 B$ were significantly (FDR $\leq 0 / 05)$ up-regulated $(+1.7$ fold) in immune versus naïve sheep on day 5 pi in the microarray analysis (Figure 3e), while $M M P-13$ was down-regulated ( -2.3 fold) in the immune group compared to naive at day 5 post-challenge (Figure $3 \mathrm{e}$ and Table 5). There was also significant up-regulation of the protease inhibitor cystatin C (CST3) in immune sheep compared to naïve at day 0 and day 5 post-challenge $(+1.4 /+1.5$ fold) (Figure 3e and Table 5). The multiplex qRT-PCR analysis confirmed transcripts for MMP-13 were expressed at significantly $(P \leq 0.05)$ lower levels in immune versus naïve sheep at day 0 , while $M M P 23 B$ gene expression showed a similar pattern at day 2 pi $(P$ $\leq 0.05$; immune vs. naive) (Figure 6). Transcripts for cystatin $\mathrm{C}$ appeared to be expressed at high but fairly consistent levels in both groups, although significantly higher levels were detected in naïve sheep than immune sheep at day 2 post-challenge (Figure 6).

\section{Immunoglobulins}

Genes featuring the "immunoglobulin" descriptor occur 31 times among the significantly (FDR $\leq 0.05$ ) up-regulated transcripts in immune animals on day 5 post-challenge compared to day 5 naïve, and 13 times in the day 2 immune versus day 0 immune group (see [34] for complete dataset). 

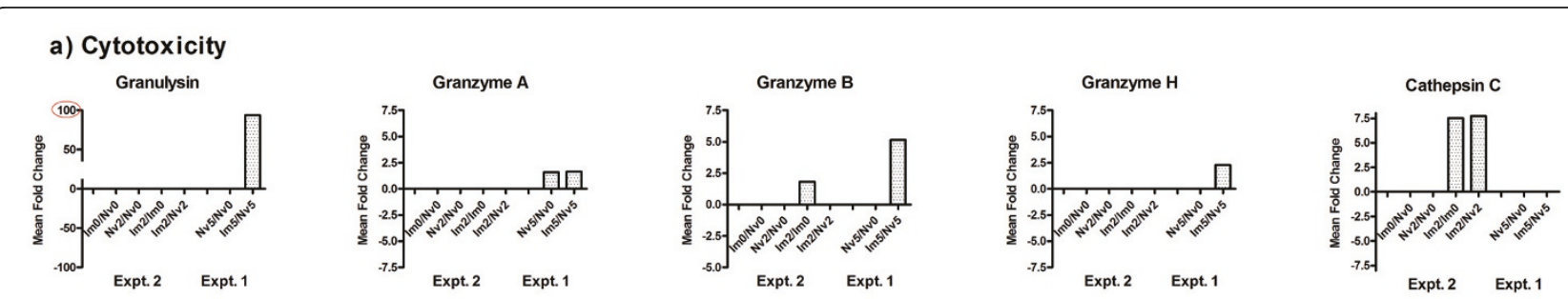

b) Mucus composition
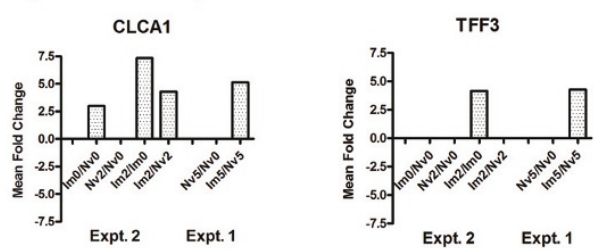

\section{c) Heat shock response}
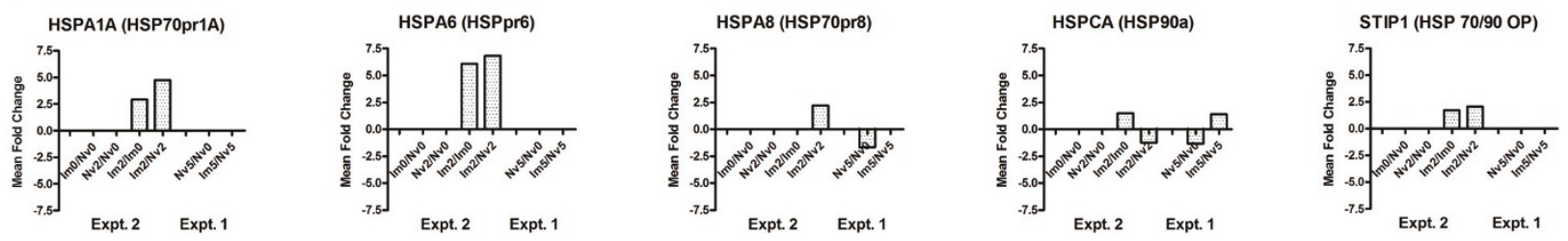

d) Proinflammatory response
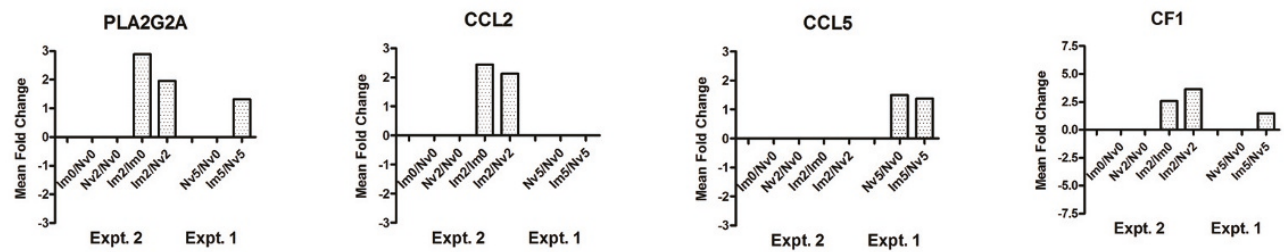

e) Tissue remodelling
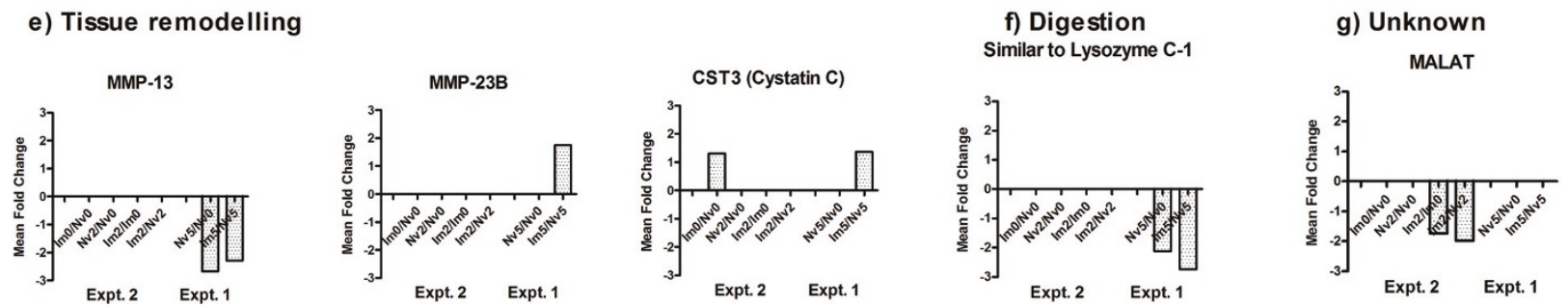

Figure 3 Key changes detected in Expt. 1 (day 5 post-challenge) and Expt. 2 (day 2 post-challenge). Summary of mean infectionassociated fold changes in the expression levels of key groups of transcripts detected from the microarray analyses. Transcripts are grouped as follows according to associated function/cell type; a) cytotoxicity, b) mucus composition, c) heat shock response, d) proinflammatory response, e) tissue remodelling (matrix metalloproteinases and inhibitors), f) nutritional (lysozyme family), g) unknown (MALAT). The groups being compared are indicated on the $y$-axis.

\section{Gastric lysozyme family}

Members of the gastric lysozyme family [38] were the most consistently down-regulated transcripts (FDR $\leq$ 0.05) detected in the Expt. 1 microarray analyses (day 5 post-challenge) (Figure $3 \mathrm{f}$ and Table 5). RT-PCR and sequence analysis have previously indicated infectionassociated down-regulation of transcripts for the ovine gastric lysozyme genes $1 A, 2 A, 3 A$ and $4 A$, and confirmed these transcripts all exhibited some level of polymorphism (Anderson and Knight; data not shown). Gastric lysozymes 1A and 4A were selected for further analysis in the multiplex qRT-PCR assay (Table 3). This analysis confirmed that transcripts for lysozymes $1 \mathrm{~A}$ and $4 \mathrm{~A}$ were both highly expressed in the naïve abomasum 

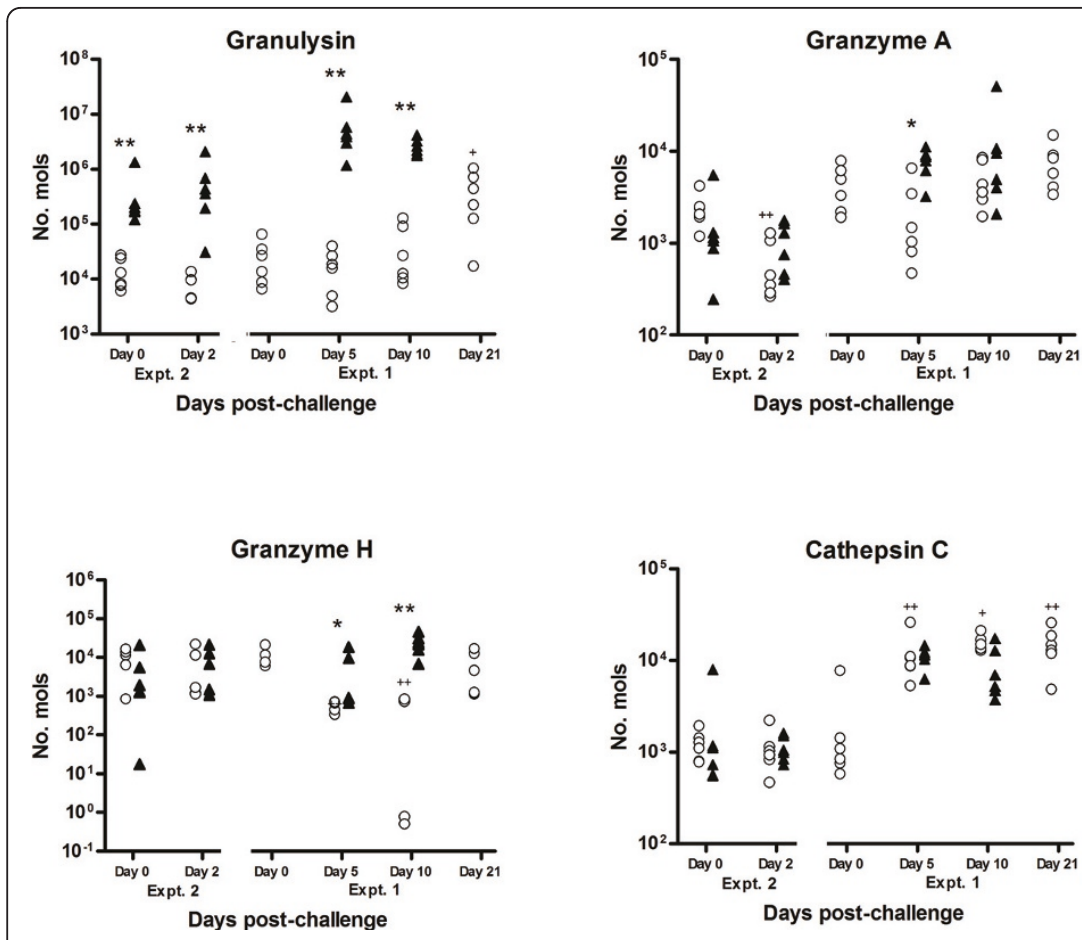

Figure 4 Results of competitive multiplex qRT-PCR analysis to investigate temporal changes in the expression levels of transcripts normally associated with cells exhibiting cytotoxicity; granulysin, granzymes A, B and H, and cathepsin C, as indicated, throughout the experiment trials summarised in Table 1 . Open circles represent data from naïve sheep; closed triangles represent data from immune ("previously infected") sheep. Significant difference between Nv and Im at same timepoint; ${ }^{*} P \leq 0.05,{ }^{* *} P \leq 0.005$, ${ }^{* * *} P \leq 0.005$; Significant difference between timepoint and day 0 of same group (where available); ${ }^{+} p \leq 0.05,{ }^{++} p \leq 0.005,{ }^{+++} p \leq 0.005$ (Mann-Whitney U-test for nonparametric data). NB.- data for granzyme $\mathrm{H}$ - model fitting failed in some samples, so $n=5$ in some groups as indicated.

and were significantly $(P \leq 0.05-0.005)$ down-regulated in immune versus naïve sheep at days 2 and 5 post-challenge, although these differences became less apparent from day 10 onwards as levels in the naïve animals reduced (Figure 7).

\section{MALAT-1}

Metastasis-associated lung adenocarcinoma transcript 1 (MALAT-1) was identified as among the most significantly (FDR $\leq 0.05)$ down-regulated transcripts in immune sheep on day 2 post-challenge (-1.8-2 fold), compared to naïve animals or day 0 (Table 4 and Figure $3 g)$. This observation from the array data was confirmed by the multiplex qRT-PCR analysis, with significantly reduced levels of MALAT-1 transcripts in immune versus naïve animals at day 0 and day 2 post-challenge (Figure 7). MALAT-1 is understood to be a novel noncoding RNA which is highly conserved across species and up-regulated during metastasis, but its function is unknown to date [39]. We also observed transcripts for "boundary element associated factor" as the most highly down-regulated transcript in immune versus naïve animals at day 5 post-challenge ( -6.5 fold, Table 5$)$; again the function of this gene product is not clear but it appears to be involved in transcriptional regulation by compartmentalization of the genome [40].

\section{Discussion}

The molecular mechanisms that contribute to protection from gastrointestinal nematodes have been extensively investigated in rodent models (e.g. reviews by [41-43]), but progress in understanding the responses to natural infections in ruminants, especially sheep, has been slower partly due to the limited range of appropriate species-specific reagents and genomics tools. Here we summarise findings using a novel ovine cDNA microarray, which is the first global transcriptomic analysis of ovine immune responses to Teladorsagia circumcincta challenge. Our data presented here are consistent with the observed increased adaptive and innate immune response taking place by days 2 and 5 postchallenge in the abomasal mucosa of sheep previously exposed to the parasite using this experimental protocol [11]. As discussed below, many of our findings highlight the importance of genes which have been investigated in rodent models of gastrointestinal nematode infection and previously highlighted in other ruminant studies, such as the expression changes in immunoglobulin 


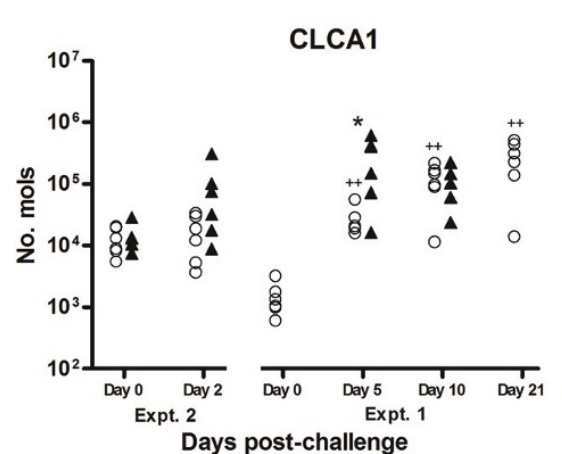

Days post-challenge

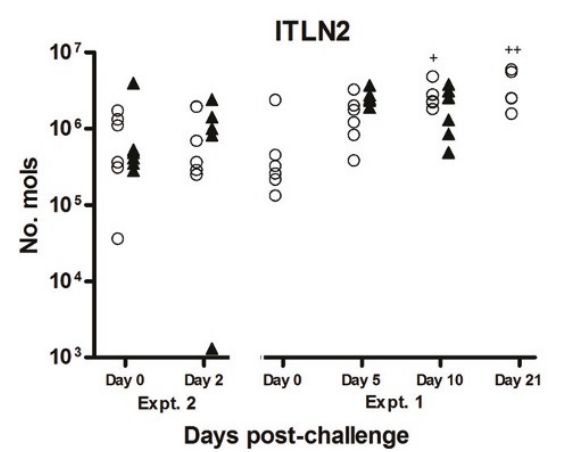

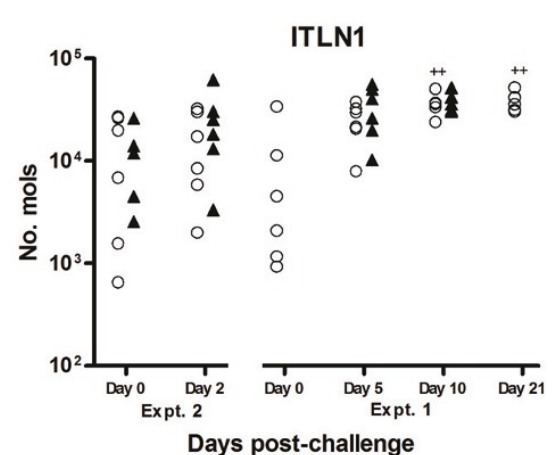

ITLN3

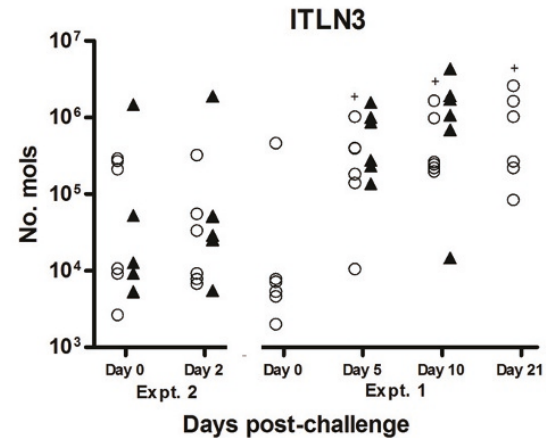

Figure 5 Results of competitive multiplex qRT-PCR analysis to investigate temporal changes in the expression levels of mucous-cell associated transcripts; CLCA1 and ITLNs 1-3, as indicated, throughout the experiment trials summarised in Table 1. Open circles represent data from naïve sheep; closed triangles represent data from immune ("previously infected") sheep. Significant difference between Nv and Im at same timepoint; ${ }^{*} P \leq 0.05,{ }^{* *} P \leq 0.005,{ }^{* * *} P \leq 0.005$; Significant difference between timepoint and day 0 of same group (where available); ${ }^{+} P \leq 0.05,{ }^{++} P \leq 0.005,{ }^{+++} P \leq 0.005$ (Mann-Whitney U-test for non-parametric data).

transcripts, mucus and mast cell products, and members of the arachidonic acid pathway, and point to common mechanisms operating in response to nematode parasitism of both the gastric and intestinal mucosa. However, we have also highlighted novel changes such as altered expression levels of granulysin, gastric lysozymes, members of the matrix-metalloprotease family, and STIP1, which indicate responses that are unique to this model or have not been identified to date.

As reported previously, in all the trials (Table 1), sheep immunised by previous infection ("immune") had significantly $(P \leq 0.01)$ lower worm burdens than naïve animals at the same timepoint, even at $48 \mathrm{~h}$ post-challenge $[4,11]$. Similarly, worms recovered from the immunised sheep showed higher levels of stunting [4]. These observations confirmed there were significantly increased anti-parasite responses in the immunised groups compared to naïe, and that these responses manifested themselves within $48 \mathrm{~h}$ of challenge. Previous work using materials from these infection trials indicated that there were clear histological and/or histochemical phenotypic differences elicited in the host response between the "naïve" and "immune" groups, such as mucosal hypertrophy, mast cell and eosinophil counts, and in mucous composition ([8,44] and Craig et al., unpublished observations). In order to characterise these differences at a molecular level we examined changes in gene expression at the transcript level in the same experimental animals.

There were some discrepancies in this study between the findings from the cDNA arrays and the multiplex qRT-PCR results, which is likely to be due, in part, to the inability of some of the cDNA probes $(+400 \mathrm{bp})$ to distinguish between groups of highly similar genes. This is particularly obvious in the case of the highly similar family of ruminant gastric lysozyme genes [38]; only the specific RT-PCR/competitive qRT-PCR techniques would have been able to reliably distinguish between transcripts for lysozymes $1 A$ and $4 A$, which are $92 \%$ identical at the DNA level. A similar explanation is likely to account for inconsistencies between the microarray and qRT-PCR findings in identifying changes in transcripts for members of the $\mathrm{C} 1$ complement family, and for the ITLN genes 1,2 and 3, which were unlikely 
to be distinguished by the ITLN2 cDNA probe on the array; there were also temporal differences in expression between the three genes (Figure 5). These findings highlight the importance of validation of cDNA array data by more sensitive techniques, such as quantitative PCRbased analyses.

As immunity to $T$. circumcincta is associated with local IgA and IgE responses typical of gastrointestinal nematode infections $[4,6]$ it is unsurprising that genes featuring the "immunoglobulin" descriptor were highly represented among the significantly up-regulated transcripts in immune animals. Our findings for immunoglobulin transcripts are consistent both with an increased adaptive response in sheep previously exposed to the parasite, and with observations from other global analyses of responses to gastrointestinal nematode infection [45-47].

Our findings highlight the universal importance of mucus components in mammalian responses to parasitic nematode infection, such as CLCA1, members of the ITLN family and trefoil factor 3 , which potentially contribute to expulsion by altering mucus composition and 

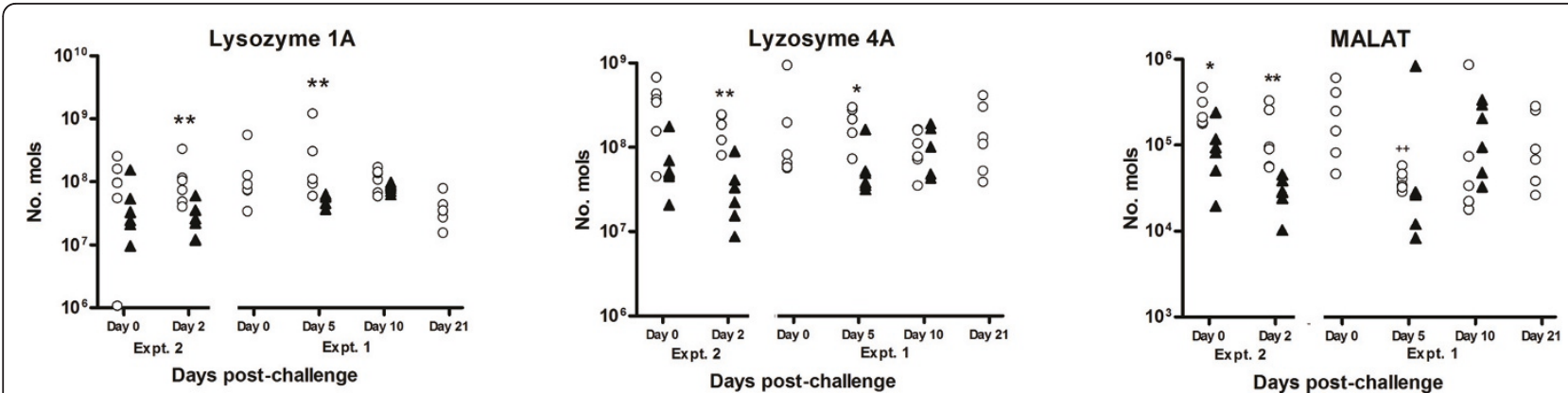

Figure 7 Results of competitive multiplex qRT-PCR analysis to investigate temporal changes in the expression levels of transcripts for lysozymes $1 \mathrm{~A}$ and $4 \mathrm{~A}$, and MALAT, as indicated, throughout the experiment trials summarised in Table 1. Open circles represent data from naïve sheep; closed triangles represent data from immune ("previously infected") sheep. Significant difference between Nv and Im at same timepoint; ${ }^{*} P \leq 0.05,{ }^{* *} P \leq 0.005,{ }^{* * *} P \leq 0.005$; Significant difference between timepoint and day 0 of same group (where available); ${ }^{+} P \leq 0.05,{ }^{+}$ ${ }^{+} P \leq 0.005,{ }^{+++} P \leq 0.005$ (Mann-Whitney U-test for non-parametric data).

making the environment of the parasite inhospitable. A similar pattern of gene expression has been identified in response of the abomasal mucosa to Haemonchus contortus infection [46]. There is a clear association between intestinal goblet cell hyperplasia, release of their effector molecules and altered mucus composition with the trapping and expulsion of gastrointestinal nematodes, mostly based on murine studies (reviewed by $[43,48,49]$. Sheep given trickle infection of $T$. circumcincta are known to exhibit hyperplasia of mucous-neck cells [14], which are phenotypically similar to goblet cells in the intestine, but this occurs as a later event in naïve sheep in response to challenge [10]. Previous work [44] has also demonstrated differences in PAS staining in naïve versus immune sheep $(P<0.05$, Kruskall-Wallis at day 10 post-challenge) from the experimental samples used in this study, indicating altered abomasal mucous composition between the two groups.

CLCA1 (the putative orthologue of CLCA3 in mice), which featured as one of the most consistently up-regulated transcripts in immune sheep, is secreted by goblet/ mucous-neck cells in association with Th2-type inflammatory responses, such as murine models of pulmonary inflammation and gastro-intestinal nematode infection [50]. We have confirmed that CLCA1 is up-regulated by IL-4 and IL-13 in a human goblet cell line [43], and by IL-4 in ovine gastric epithelial cells (Knight et al., in preparation). The significant up-regulation of transcripts for the mucous cell product trefoil factor 3 (TFF3) in immune animals compared to naïve was in contrast to TFF2, which is highly down-regulated (Tables 4 and 5). TFF3 is IL-4/IL-13-regulated and interacts with the mucin MUC2 (not on array) to alter mucus viscosity, with which it co-localises in human intestinal goblet cells, and up-regulation of both these mucus components has been associated with responses to nematode infection in mice (reviewed by [43]). Up-regulation of
TFF3 and down-regulation of TFF2 transcripts has also been demonstrated in the abomasal mucosa of sheep during the response to $H$. contortus $[46,51,52]$, thus switching to a more "intestinal" phenotype in terms of TFF expression.

The multiplex qRT-PCR analyses showed the galactose-binding lectins ITLNs 1,2 and 3 were significantly up-regulated in response to challenge in naïve sheep, with earlier up-regulation of ITLN3 than ITLNs -1 and -2 (Figure 5). ITLN protein is localised to mucous neck cells in the abomasal mucosa, and highly up-regulated in infected compared to worm-free naïve sheep $[27,35]$. We also observed infection-associated up-regulation of transcripts for two other galactose-binding lectins; galectin 1, which is thought to bind gastrointestinal mucins [53], and galectin 4, which has been shown to be localised to gastric mucous cells in mice [54]. There is a clear temporal association between expression of members of the intelectin family by murine intestinal goblet cells and resistance to gastrointestinal nematode infection in mice [55,56]. The ITLN family, like CLCA1, are highly regulated by Th2 cytokines in murine and human goblet cells [43], and this has also been confirmed in ovine tracheal goblet cells [57] and gastric epithelial cultures (Knight et al, in preparation). Both $C L C A 1$ and intelectin protein were up-regulated in mucosal washings from previously infected, but not naïve, animals [58] indicating they act concordantly as part of an increased Th2-type response to alter mucus composition. It is possible that members of both the intelectin and galectin family are involved in interaction with mucins to change the rheological properties or adhesiveness of the mucus, and/or adhere to the worms to exert effector function or target them for immune clearance.

Significant up-regulation of the high affinity IgE receptor in immune animals day 2 and day 5 post-challenge, 
along with up-regulation of cathepsin $\mathrm{C}$, is consistent with an increased mast cell response in this group. $\mathrm{T}$ cell mediated mucosal mast cell hyperplasia, accompanied by release of mast-cell mediators, is a characteristic feature of gastrointestinal nematode infections in mammals (reviewed by [43,59]). While numbers of mast cells (globule leucocytes) in the ovine abomasal mucosa are normally very low in uninfected sheep, they markedly increase in response to $T$. circumcincta infection in sensitised sheep, accompanied by release of sheep mast cell protease (SMCP) [13,60]. An assessment of the samples used in this study confirmed that the immune group had significantly higher numbers of mast cells than the naïve group at days $0,2,5$ and 10 post-challenge, with the naïve animals showing very little increase in mucosal mast cell numbers in response to challenge ([8] and Craig et al., unpublished data).

We see evidence of up-regulation of a number of transcripts associated with eicosanoid metabolism, in particular PLA2G2A, which can initiate and regulate inflammation [61]. Increased synthesis of phospholipase and other members of the arachidonic acid cascade have been associated with intestinal nematode infection in rodents, cattle and swine [62-66], and so are likely to play a common key role in the induction and/or regulation of nematode-induced allergic inflammation; we would postulate a similar set of events occurring in the ovine abomasal mucosa in response to parasite challenge. Members of the complement cascade also appear to be up-regulated in response to $T$. circumcincta challenge; up-regulation of the complement $\mathrm{C} 1$ and $\mathrm{C} 4$ has similarly been linked to resistance to intestinal nematode infection in cattle [65]. Complement activation serves to initiate and propagate pro-inflammatory responses, although the role of complement in immunity to parasitic helminths is unclear [67]. Proteomic analysis has indicated complement and other plasma proteins are up-regulated in the mucosa of $T$. circumcinta infected versus naïve sheep, although these are likely to be derived from plasma rather than local expression [58].

We observed significant up-regulation of the chemokines CCL2 and CCL5 in response to larval challenge (Table 4, Figures 3c) and 6). CCL2, which is produced by a range of cell types including mast cells [68] has been shown to be released locally in response to gastrointestinal nematode infection in mice, and has been implicated in resistance to Trichuris muris by steering towards a Th2-type response [69]. CCL5 is chemotactic for $\mathrm{T}$ cells, eosinophils, and basophils and implicated in a wide range of inflammatory diseases [70]. A previous RT-PCR-based analysis has shown that the abomasal mucosa is a source for a range of chemokine transcripts, and that CCL5 transcripts are up-regulated in response to $T$. circumcincta challenge (Griffith et al., unpublished observations).

One of the most surprising findings from this study, which has not been evidenced from rodent models, is the striking up-regulation of transcripts for granulysin in immune animals, which is normally associated with antimicrobial activity [71], along with other transcripts (granzymes, cathepsin C) normally associated with lymphocytes exhibiting cytotoxicity. Granulysin and NKlysin are secreted, antimicrobial lipid-binding proteins belonging to the saposin family [71]. They have been identified in human, swine and bovine cytotoxic $\mathrm{T}$ lymphocytes and natural killer (NK) cells [72,73], but no murine counterpart has been identified to date. Granulysin is active against a broad range of intracellular and extracellular microbes [74], and granulysin activity has also been associated with apoptosis and necrosis of keratinocytes [75]. Granzymes A, B and H, like granulysin, are also normally associated with the activity of cytotoxic T-cells and NK cells [76], while cathepsin C is required for the processing and correct functioning of granzymes A and B and mast cell proteinases [77]. Interestingly, the pattern of expression of granulysin transcripts did not closely parallel that of the granzymes and cathepsin C (Figure 4), which suggests a different cellular source in the abomasal mucosa. This is the first time this molecule has been associated with gastrointestinal nematode infection, and the first association of this molecule with ovine disease. We have recently confirmed increased levels of granulysin protein in the abomasal mucosa of immune, but not naïve, sheep, and the potential biological role of granulysin in nematode infection is under further investigation (Griffith et al, in preparation).

Expression levels of transcripts for a number of heat shock proteins were significantly altered in the microarray analyses; in particular STIP1, which facilitates the association of the HSP70/90 complex which is implicated in the folding/regulation of a range of signalling proteins [78], was significantly increased in response to challenge (Figure 6). Host heat shock proteins are expressed constitutively in all cells but synthesis is increased in response to certain stressors or infection [79]. There has been little evidence to identify a direct role for heat shock proteins in gastrointestinal nematode infection, although $T$. spiralis has been shown to elicit host heat shock protein production during muscle migration [80]. The up-regulation and/or release of heat shock proteins is likely to be solely the effect of cellular damage caused to the mucosa by the parasite, but their release may also activate immune cells or facilitate antigen presentation $[79,81]$.

Both the microarray and multiplex qRT-PCR analysis demonstrated significant down-regulation of transcripts 
for $M M P-13$, as well as apparently high levels of cystatin $C$ transcript expression. In a separate study (Knight et al., unpublished data), we have detected markedly decreased levels of transcripts for MMP-7 and TIMP-1 (tissue inhibitor of metalloproteinases) in immune versus naïve sheep exposed to $T$. circumcincta (MMP-7 and TIMP-1 were not this on array). Matrix metalloproteinases are implicated in a wide range of processes including regulation of inflammatory responses such as modulating response to cytokines and activation of $\beta$ defensins, as well as tissue dissolution/remodelling $[82,83]$ and have been associated with T-cell mediated tissue damage to the gut mucosa [84]. The apparently higher levels of these transcripts in naïve compared to immune sheep may reflect increased tissue damage that is generally observed in the abomasa of animals that have not built up a level of immunity to the parasite. It is also possible that they have a role in inflammatory processes/tissue remodelling that is "replaced" in previously exposed sheep by mast cell proteases, which may have a similar function [85], following expansion of the mucosal mast cell population. The altered profile in matrix metalloproteinases may also have implications in interaction with incoming larvae, as helminth parasites are understood to produce proteinase inhibitors to protect themselves from degradation by host proteinases [86], and parasites of the gastrointestinal tract can interact with host proteolytic pathways with immunomodulatory effects $[87,88]$. Furthermore, T. circumcincta larvae abundantly produce the cysteine protease cathepsin $F$ [89], which raises the possibility that high local levels of cystatin $C$ could serve a protective function. The potential interaction of these matrix-metalloproteases and protease inhibitors with proteases or inhibitors produced by incoming larvae would merit further investigation.

The most consistently down-regulated transcripts in immune versus naïve sheep detected at day 5 post-challenge were members of the ruminant gastric lysozyme family. It should be noted that the array contained more than 50 spots representing members of this family which were down-regulated in the day 5 immune vs. naive comparison, and 5 spots in the day 5 naïve vs. day 0 naïve comparison. The large numbers of significant spots may be partly due to the overrepresentation of the lysozyme family on the cDNA chip, having a high proportion of sequences in the KN511 library (2.5\%) [90]. There are four highly similar ruminant gastric lysozyme genes, which are thought to have evolved from the lysozyme C gene family by gene-duplication events [38]. They are highly expressed in the ovine abomasum and are thought to act as a major digestive enzyme, functional at low $\mathrm{pH}$, for the large amounts of bacteria entering from the rumen, by breaking down peptidoglycan cell walls which cannot be hydrolysed by conventional digestive enzymes. This analysis confirmed that transcripts for lysozymes $1 \mathrm{~A}$ and $4 A$ were both highly expressed in the naïve abomasum and significantly down-regulated in immune versus naïve sheep at days 2 and 5 post-challenge, although these differences became less apparent from day 10 onwards as levels in the naïve animals reduced (Figure 7). This pattern is in contrast to a parallel proteomics study, where lysozyme $4 A$ increased in previously infected animals compared to naïve at day 0 and day 2 post-challenge (Brown, Pemberton et al., in preparation) and members of the lysozyme family were found to be up-regulated in abomasal epithelial extracts and mucosal washes from previously infected versus naïve sheep [58]. This disparity is likely to be due to differing rates of transcription, processing and storage of the gastric lysozymes prior to secretion. Sheep parasitized by $T$. circumcincta show diminution of parietal cell number, raised abomasal $\mathrm{pH}$ and hypergastrinaemia [14,91], so we could speculate that the alterations in lysozyme production, and the possible inability of lysozymes to function in the raised $\mathrm{pH}$ of the abomasum, both reflect these changes and may contribute to the resultant nutritional loss seen in infected animals.

In summary, the up-regulated expression of mucouscell related transcripts such as CLCA1, TFF3 and ITLNs, as well as transcripts for the high affinity IgE receptor, CCL2, and members of the arachidonic acid pathway in response to ovine gastric nematode infection, parallel findings from mouse models of intestinal nematode infection by ourselves and others $[43,56,92]$. Many of these changes reflect a common Th2-driven immune response occurring across species and in both areas of the gastrointestinal tract. However, other findings point to novel changes, such as the distinct local up-regulation of granulysin in immune sheep, a gene which is present in humans, cattle and pigs but not mice, and the alteration in the gastric lysozyme profile which is unique to ruminants.

As can be seen from the pattern of expression of the gastric lysozymes discussed previously, it needs to be borne in mind that changes in the transcriptome may not directly reflect contemporaneous changes in local levels of the corresponding protein, many of which are stored before subsequent release into the local microenvironment. Many of the changes described here are likely to reflect the pronounced cellular changes in the abomasal mucosa induced by exposure to T. circumcincta larvae. Nevertheless, the data presented here gives valuable insights into some of the molecular mechanisms that may be operating at the ovine host-parasite interface to control gastric nematode infection. 


\section{Additional material}

\section{Additional file 1: Table S1 Details of primers and PCR conditions} used for RT-PCR analysis. Details of primers and PCR conditions used for RT-PCR analysis, and sequences used to design PCR probes. Table S2 Total numbers of genes whose expression levels were significantly altered detected in each hybridisation experiment Total numbers of genes whose expression levels were significantly altered (Benjamini \& Hochberg FDR 50.05 ) detected in each hybridisation experiment; (Table S2a: Expt.1; day 5 post-challenge and Table S2b: Expt. 2; day 2 postchallenge) including dye interactions.

Additional file 2: Table S3 Significantly highly represented networks identified using Ingenuity Pathways Analysis software (Ingenuity ${ }^{\mathbb{B}_{\circledast}}$ Systems, [26]). Networks that were significantly highly represented ( $P \leq 10-10$; Fischer's exact test) identified from the Imd0/Nvd0 and Imd2/ Imd0 datasets from Expt. 2 (see Table II), using Ingenuity Pathways Analysis software (Ingenuity ${ }^{\mathbb{B}_{\circledast}}$ Systems, [26]). Table S4 Canonical pathways identified using Ingenuity Pathways Analysis software (Ingenuity ${ }^{\mathbb{B}_{\circledast}}$ Systems, http://www.ingenuity.com). The top 20 most significant canonical pathways from the Imd0/Nvd0 and Imd2/Imd0 datasets from Expt. 2 (See Table II), identified using Ingenuity Pathways Analysis software (Ingenuity ${ }^{\mathbb{B}_{\circledast}}$ Systems, [26]), are shown.

\section{Acknowledgements}

We thank Steve Smith and Aileen Halliday (MRI) for assistance with and access to tissue samples collected at post-mortem and Sequenom Inc, San Diego, CA for running the multiplex qRT-PCR assays (Sequenom ${ }^{\circledR}$ MasSARRAY ${ }^{\circledR}$ System). This work was funded by DEFRA/SFC (VT0102) and the BBSRC (BB/E01867X/1).

\section{Author details}

${ }^{1}$ The Roslin Institute and R(D)SVS, University of Edinburgh, Roslin, Midlothian, EH25 9RG, Scotland, UK. ${ }^{2}$ Moredun Research Institute, Pentlands Science Park, Bush Loan, Penicuik, Midlothian, EH26 OPZ, Scotland, UK.

\section{Authors' contributions}

PK planned and supervised the study and drafted the manuscript, SG carried out the sequencing and RT-PCR analysis of granulysin, JP assisted with postmortem sample collection and carried out RNA extractions/QC checks, AP assisted with interpretation of data and participated in manuscript preparation, LG carried out the sequence analysis of MMPs and inhibitors, KA carried out the sequence analysis of the lysozyme family, RT supervised the microarray experiments, SS carried out the hybridisations, DW carried out statistical analysis of the microarray experiments, MF carried out annotation of the ARK-Genomics 0 . aries $12 \mathrm{~K}$ v1.0 array and assisted with data processing, AA supervised the microarray experiments and advised on manuscript preparation, SB carried out the Ingenuity analysis and assisted with presentation of the output, DS supervised the experimental infections and advised on manuscript preparation, HM and IM conceived and obtained the funding for the VTRI overall project and HM advised on manuscript preparation. All authors read and approved the final manuscript.

\section{Competing interests}

The authors declare that they have no competing interests.

Received: 4 October 2010 Accepted: 17 June 2011

Published: 17 June 2011

\section{References}

1. Bartley DJ, Jackson F, Jackson E, Sargison N: Characterisation of two triple resistant field isolates of Teladorsagia from Scottish lowland sheep farms. Vet Parasitol 2004, 123:189-199.

2. Smith WD, Jackson F, Jackson E, Williams J: Local immunity and Ostertagia circumcincta: changes in the gastric lymph of immune sheep after a challenge infection. J Comp Pathol 1983, 93:479-488.

3. Smith WD, Jackson F, Jackson E, Williams J, Miller HR: Manifestations of resistance to ovine ostertagiasis associated with immunological responses in the gastric lymph. J Comp Pathol 1984, 94:591-601.
4. Halliday AM, Routledge CM, Smith SK, Matthews JB, Smith WD: Parasite loss and inhibited development of Teladorsagia circumcincta in relation to the kinetics of the local IgA response in sheep. Parasite Immunol 2007, 29:425-434.

5. Smith WD, Jackson F, Jackson E, Graham R, Williams J, Willadsen SM, Fehilly CB: Transfer of immunity to Ostertagia circumcincta and IgA memory between identical sheep by lymphocytes collected from gastric lymph. Res Vet Sci 1986, 41:300-306.

6. Stear MJ, Strain S, Bishop SC: How lambs control infection with Ostertagia circumcincta. Vet Immunol Immunopathol 1999, 72:213-218.

7. Huntley JF, Schallig HD, Kooyman FN, Mackellar A, Jackson F, Smith WD: IgE antibody during infection with the ovine abomasal nematode, Teladorsagia circumcincta: primary and secondary responses in serum and gastric lymph of sheep. Parasite Immunol 1998, 20:565-571.

8. Craig NM: Cytokine gene expression in naive and previously infected sheep and lambs after challenge with the abomasal nematode Teladorsagia circumcincta. PhD thesis University of Edinburgh, UK; 2010.

9. Craig NM, Miller HR, Smith WD, Knight PA: Cytokine expression in naive and previously infected lambs after challenge with Teladorsagia circumcincta. Vet Immunol Immunopathol 2007, 120:47-54.

10. Scott I, Khalaf S, Simcock DC, Knight CG, Reynolds GW, Pomroy WE, Simpson HV: A sequential study of the pathology associated with the infection of sheep with adult and larval Ostertagia circumcincta. Vet Parasitol 2000, 89:79-94.

11. Halliday AM, Morrison WI, Smith WD: Kinetics of the local cellular response in the gastric lymph of immune and susceptible sheep to infection with Teladorsagia circumcincta. Parasite Immunol 2009, 31:402-411.

12. Huntley JF, Jackson F, Coop RL, Macaldowie C, Houdijk JG, Familton AS, Xieh HL, Stankiewicz M, Sykes AR: The sequential analysis of local inflammatory cells during abomasal nematode infection in periparturient sheep. Vet Immunol Immunopathol 2004, 97:163-176.

13. Balic A, Bowles VM, Liu YS, Meeusen EN: Local immune responses in sensitized sheep following challenge infection with Teladorsagia circumcincta. Parasite Immunol 2003, 25:375-381.

14. Scott I, Hodgkinson SM, Khalaf S, Lawton DE, Collett MG, Reynolds GW, Pomroy WE, Simpson HV: Infection of sheep with adult and larval Ostertagia circumcincta: abomasal morphology. Int J Parasitol 1998, 28:1383-1392.

15. Miller HR, Jackson F, Newlands G, Appleyard WT: Immune exclusion, a mechanism of protection against the ovine nematode Haemonchus contortus. Res Vet Sci 1983, 35:357-363.

16. Miller HRP, Jackson F, Newlands GFJ, Huntley JF: Rapid expulsion of gastrointestinal nematodes in sheep: a role for immediate hypersensitive reactions in the mucosa. In Immunology of the Sheep. Edited by: Morris B, Myasaka M. Roche, Basle; 1986:460-482.

17. Knight PA, Pate J, Smith WD, Miller HR: An ovine chitinase-like molecule, chitinase-3 like-1 (YKL-40), is up-regulated in the abomasum in response to challenge with the gastrointestinal nematode, Teladorsagia circumcincta. Vet Immunol Immunopathol 2007, 120:55-60.

18. ARK-Genomics: Centre for Comparative \& Functional Genomics website. [http://www.ark-genomics.org].

19. Smith S, et al: ARK-Genomics Conference 2008: 3rd International Symposium on Animal Functional Genomics, ISAFG-P71.[http://www.arkgenomics.org/downloads/SAFG-2008-Abstracts.pdf].

20. Baird D, Johnstone $P$, Wilson T: Normalization of microarray data using a spatial mixed model analysis which includes splines. Bioinformatics 2004, 20:3196-3205.

21. Smyth GK, Speed T: Normalization of cDNA microarray data. Methods 2003, 31:265-273.

22. Smyth GK: Limma: linear models for microarray data. In Bioinformatics and Computational Biology Solutions using $R$ and Bioconductor Gentleman $R$. Edited by: Carey V, Dudoit S, Irizarry R, Huber W. Springer, New York; 2005:397-420.

23. Smyth GK: Linear models and empirical bayes methods for assessing differential expression in microarray experiments. Stat Appl Genet Mol Biol 2004, 3:Article3.

24. Benjamini $Y$, Hochberg $Y$ : Controlling the false discovery rate: a practical and powerful approach to multiple testing. J R Statist Soc B 1995, 57:289-300.

25. Jaffrezic F, de Koning DJ, Boettcher PJ, Bonnet A, Buitenhuis B, Closset R, Dejean S, Delmas C, Detilleux JC, Dovc P, Duval M, Foulley JL, Hedegaard J, 
Hornshoj H, Hulsegge I, Janss L, Jensen K, Jiang L, Lavric M, Le Cao KA, Lund MS, Malinverni R, Marot G, Nie H, Petzl W, Pool MH, Robert-Granie C, San Cristobal M, van Schothorst EM, Schuberth HJ, Sorensen P, Stella A, Tosser-Klopp G, Waddington D, Watson M, Yang W, Zerbe H, Seyfert HM: Analysis of the real EADGENE data set: comparison of methods and guidelines for data normalisation and selection of differentially expressed genes (open access publication). Genet Sel Evol 2007, 39:633-650.

26. Ingenuity Systems, Inc. website. [http://www.ingenuity.com].

27. French AT, Knight PA, Smith WD, Brown JK, Craig NM, Pate JA, Miller HR, Pemberton AD: Up-regulation of intelectin in sheep after infection with Teladorsagia circumcincta. Int J Parasitol 2008, 38:467-475.

28. The National Center for Biotechnology Information primer designing tool Primer3 and BLAST. [http://www.ncbi.nlm.nih.gov/tools/primer-blast/].

29. European Bioinformatics Institute Tools for Sequence Analysis. [http:// www.ebi.ac.uk/Tools/sequence.html].

30. The National Center for Biotechnology Information website. [http://www. ncbi.nlm.nih.gov].

31. The Ensembl Genome Browser. [http://www.ensembl.org/].

32. The Sequenom ${ }^{\mathbb{B}}$ Gene Expression Analysis website. [http://www. sequenom.com/Genetic-Analysis/Applications/QGE-Gene-Expression].

33. Andell $Y$, et al: Multiplexed Gene Expression Analysis Using Competitive PCR and MassARRAY ${ }^{T M}$. [http://www.sequenom.com/getdoc/564717df-04374701-8f60-78ec61d95d09/Multiplexed_Gene_Expression_Analysis].

34. The ArrayExpress Archive. [http://www.ebi.ac.uk/arrayexpress/], - Accession numbers: Expt. 1: E-TABM-1149; Expt. 2: E-TABM-1150.

35. French AT, Knight PA, Smith WD, Pate JA, Miller HR, Pemberton AD: Expression of three intelectins in sheep and response to a Th2 environment. Vet Res 2009, 40:53.

36. McAleese SM, Pemberton AD, McGrath ME, Huntley JF, Miller HR: Sheep mast-cell proteinases- 1 and -3 : cDNA cloning, primary structure and molecular modelling of the enzymes and further studies on substrate specificity. Biochem J 1998, 333:801-809.

37. Pemberton $A D$, McAleese $S M$, Huntley JF, Collie DD, Scudamore $C L$, McEuen AR, Walls AF, Miller HR: cDNA sequence of two sheep mast cell tryptases and the differential expression of tryptase and sheep mast cell proteinase-1 in lung, dermis and gastrointestinal tract. Clin Exp Allergy 2000, 30:818-832.

38. Wen Y, Irwin DM: Mosaic evolution of ruminant stomach lysozyme genes. Mol Phylogenet Evol 1999, 13:474-482.

39. Ji P, Diederichs S, Wang W, Boing S, Metzger R, Schneider PM, Tidow N, Brandt B, Buerger H, Bulk E, Thomas M, Berdel WE, Serve H, Muller-Tidow C: MALAT-1, a novel noncoding RNA, and thymosin beta4 predict metastasis and survival in early-stage non-small cell lung cancer. Oncogene 2003, 22:8031-8041.

40. Pathak RU, Rangaraj N, Kallappagoudar S, Mishra K, Mishra RK: Boundary element-associated factor $32 \mathrm{~B}$ connects chromatin domains to the nuclear matrix. Mol Cell Biol 2007, 27:4796-4806.

41. Artis D, Grencis RK: The intestinal epithelium: sensors to effectors in nematode infection. Mucosal Immunol 2008, 1:252-264.

42. Nair MG, Guild KJ, Artis D: Novel effector molecules in type 2 inflammation: lessons drawn from helminth infection and allergy. J Immunol 2006, 177:1393-1399.

43. Knight PA, Brown JK, Pemberton AD: Innate immune response mechanisms in the intestinal epithelium: potential roles for mast cells and goblet cells in the expulsion of adult Trichinella spiralis. Parasitology 2008, 135:655-670

44. French AT: The co-regulation of the mucus associated molecules intelectin, resistin like molecule beta and beta galactoside alpha 2,3 sialyl transferease in a T helper celltype 2 response. PhD thesis University of Edinburgh, UK; 2008.

45. Diez-Tascon C, Keane OM, Wilson T, Zadissa A, Hyndman DL, Baird DB, McEwan JC, Crawford AM: Microarray analysis of selection lines from outbred populations to identify genes involved with nematode parasite resistance in sheep. Physiol Genomics 2005, 21:59-69.

46. Rowe A, Gondro C, Emery D, Sangster N: Sequential microarray to identify timing of molecular responses to Haemonchus contortus infection in sheep. Vet Parasitol 2009, 161:76-87.

47. Andronicos N, Hunt P, Windon R: Expression of genes in gastrointestinal and lymphatic tissues during parasite infection in sheep genetically resistant or susceptible to Trichostrongylus colubriformis and Haemonchus contortus. Int J Parasitol 2010, 40:417-429.

48. de Veer MJ, Kemp JM, Meeusen EN: The innate host defence against nematode parasites. Parasite Immunol 2007, 29:1-9.

49. Miller HRP, Knight PA, Pemberton AD: Mucus; modulation by the $\mathrm{TH} 2$ response to enhance an innate defensive barrier against gut nematodes. Parasite Immunol 2006, 28:259-262.

50. Gibson A, Lewis AP, Affleck K, Aitken AJ, Meldrum E, Thompson N: hCLCA1 and $\mathrm{mCLCA} 3$ are secreted non-integral membrane proteins and therefore are not ion channels. J Biol Chem 2005, 280:27205-27212.

51. Dunphy JL, Balic A, Barcham GJ, Horvath AJ, Nash AD, Meeusen EN: Isolation and characterization of a novel inducible mammalian galectin. J Biol Chem 2000, 275:32106-32113.

52. Ingham A, Reverter A, Windon R, Hunt P, Menzies M: Gastrointestinal nematode challenge induces some conserved gene expression changes in the gut mucosa of genetically resistant sheep. Int J Parasitol 2008, 38:431-442.

53. Wasano K, Hirakawa Y: Recombinant galectin-1 recognizes mucin and epithelial cell surface glycocalyces of gastrointestinal tract. J Histochem Cytochem 1997, 45:275-283

54. Nio-Kobayashi J, Takahashi-Iwanaga H, Iwanaga T: Immunohistochemical localization of six galectin subtypes in the mouse digestive tract. J Histochem Cytochem 2009, 57:41-50

55. Pemberton AD, Knight PA, Gamble J, Colledge WH, Lee JK, Pierce M, Miller HR: Innate BALB/c enteric epithelial responses to Trichinella spiralis: inducible expression of a novel goblet cell lectin, intelectin-2, and its natural deletion in C57BL/10 mice. J Immunol 2004, 173:1894-1901.

56. Datta R, deSchoolmeester ML, Hedeler C, Paton NW, Brass AM, Else K: Identification of novel genes in intestinal tissue that are regulated after infection with an intestinal nematode parasite. Infect Immun 2005, 73:4025-4033.

57. French AT, Bethune JA, Knight PA, McNeilly TN, Wattegedera S, Rhind S, Miller HR, Pemberton AD: The expression of intelectin in sheep goblet cells and up-regulation by interleukin-4. Vet Immunol Immunopathol 2007, 120:41-46.

58. Athanasiadou S, Pemberton A, Jackson F, Inglis N, Miller HR, Thevenod F, Mackellar A, Huntley JF: Proteomic approach to identify candidate effector molecules during the in vitro immune exclusion of infective Teladorsagia circumcincta in the abomasum of sheep. Vet Res 2008, 39:58.

59. Miller HR: Mucosal mast cells and the allergic response against nematode parasites. Vet Immunol Immunopathol 1996, 54:331-336.

60. Huntley JF, Gibson S, Brown D, Smith WD, Jackson F, Miller HR: Systemic release of a mast cell proteinase following nematode infections in sheep. Parasite Immunol 1987, 9:603-614.

61. Gilroy DW, Newson J, Sawmynaden P, Willoughby DA, Croxtall JD: A novel role for phospholipase A2 isoforms in the checkpoint control of acute inflammation. FASEB J 2004, 18:489-498.

62. Larsh JE Jr: Trichinella spiralis: phospholipase in sensitized mice after challenge. Exp Parasitol 1975, 37:233-238.

63. Brown JK, Knight PA, Thornton EM, Pate JA, Coonrod S, Miller HR, Pemberton AD: Trichinella spiralis induces de novo expression of group IVC phospholipase A2 in the intestinal epithelium. Int J Parasitol 2008, 38:143-147.

64. Goven AJ, DeBuysscher EV: Intestinal phospholipase B activity in swine inoculated with Trichinella spiralis. Am J Vet Res 1979, 40:1469-1471.

65. Araujo RN, Padilha T, Zarlenga D, Sonstegard T, Connor EE, Van Tassel C, Lima WS, Nascimento E, Gasbarre LC: Use of a candidate gene array to delineate gene expression patterns in cattle selected for resistance or susceptibility to intestinal nematodes. Vet Parasitol 2009, 162:106-115.

66. Li RW, Gasbarre LC: A temporal shift in regulatory networks and pathways in the bovine small intestine during Cooperia oncophora infection. Int J Parasitol 2009, 39:813-824.

67. Giacomin PR, Gordon DL, Botto M, Daha MR, Sanderson SD, Taylor SM, Dent LA: The role of complement in innate, adaptive and eosinophildependent immunity to the nematode Nippostrongylus brasiliensis. Mol Immunol 2008, 45:446-455.

68. Brown JK, Knight PA, Wright SH, Thornton EM, Miller HR: Constitutive secretion of the granule chymase mouse mast cell protease- 1 and the chemokine, CCL2, by mucosal mast cell homologues. Clin Exp Allergy 2003, 33:132-146. 
69. de Schoolmeester ML, Little MC, Rollins BJ, Else KJ: Absence of CC chemokine ligand 2 results in an altered Th1/Th2 cytokine balance and failure to expel Trichuris muris infection. J Immunol 2003, 170:4693-4700.

70. Navratilova Z: Polymorphisms in CCL2\&CCL5 chemokines/chemokine receptors genes and their association with diseases. Biomed Pap Med Fac Univ Palacky Olomouc Czech Repub 2006, 150:191-204.

71. Bruhn $\mathrm{H}$ : A short guided tour through functional and structural features of saposin-like proteins. Biochem J 2005, 389:249-257.

72. Endsley JJ, Furrer JL, Endsley MA, McIntosh MA, Maue AC, Waters WR, Lee DR, Estes DM: Characterization of bovine homologues of granulysin and NK-lysin. J Immunol 2004, 173:2607-2614.

73. Endsley JJ, Furrer JL, McIntosh MA, Estes DM: Antimicrobial activity of a bovine granulysin homologue. Faseb J 2003, 17:C171-C171.

74. Stenger S, Hanson DA, Teitelbaum R, Dewan P, Niazi KR, Froelich CJ, Ganz T, Thoma-Uszynski S, Melian A, Bogdan C, Porcelli SA, Bloom BR, Krensky AM, Modlin RL: An antimicrobial activity of cytolytic T cells mediated by granulysin. Science 1998, 282:121-125.

75. Chung WH, Hung SI, Yang JY, Su SC, Huang SP, Wei CY, Chin SW, Chiou CC, Chu SC, Ho HC, Yang CH, Lu CF, Wu JY, Liao YD, Chen YT: Granulysin is a key mediator for disseminated keratinocyte death in Stevens-Johnson syndrome and toxic epidermal necrolysis. Nat Med 2008, 14:1343-1350.

76. Chowdhury D, Lieberman J: Death by a thousand cuts: granzyme pathways of programmed cell death. Annu Rev Immunol 2008, 26:389-420.

77. Meade $J$, de Wynter EA, Brett P, Sharif SM, Woods CG, Markham AF, Cook GP: A family with Papillon-Lefevre syndrome reveals a requirement for cathepsin C in granzyme B activation and NK cell cytolytic activity. Blood 2006, 107:3665-3668.

78. Daniel S, Bradley G, Longshaw VM, Soti C, Csermely P, Blatch GL: Nuclear translocation of the phosphoprotein Hop (Hsp70/Hsp90 organizing protein) occurs under heat shock, and its proposed nuclear localization signal is involved in Hsp90 binding. Biochim Biophys Acta 2008, 1783:1003-1014.

79. Wallin RP, Lundqvist A, More SH, von Bonin A, Kiessling R, Ljunggren HG: Heat-shock proteins as activators of the innate immune system. Trends Immunol 2002, 23:130-135.

80. Martinez J, Perez Serrano J, Bernadina WE, Rodriguez-Caabeiro F: Influence of parasitization by Trichinella spiralis on the levels of heat shock proteins in rat liver and muscle. Parasitology 1999, 118:201-209.

81. Stewart GR, Young DB: Heat-shock proteins and the host-pathogen interaction during bacterial infection. Curr Opin Immunol 2004, 16:506-510.

82. Burke $B$ : The role of matrix metalloproteinase 7 in innate immunity. Immunobiology 2004, 209:51-56.

83. Parks WC, Wilson CL, López-Boado YS: Matrix metalloproteinases as modulators of inflammation and innate immunity. Nat Rev Immunol 2004, 4:617-629.

84. Di Sabatino A, Pickard KM, Rampton D, Kruidenier L, Rovedatti L, Leakey NA, Corazza GR, Monteleone G, MacDonald TT: Blockade of transforming growth factor beta upregulates T-box transcription factor T-bet, and increases T helper cell type 1 cytokine and matrix metalloproteinase-3 production in the human gut mucosa. Gut 2008, 57:605-612.

85. Miller HR, Pemberton AD: Tissue-specific expression of mast cell granule serine proteinases and their role in inflammation in the lung and gut. Immunology 2002, 105:375-390.

86. Knox DP: Proteinase inhibitors and helminth parasite infection. Parasite Immunol 2007, 29:57-71.

87. Antalis TM, Shea-Donohue T, Vogel SN, Sears C, Fasano A: Mechanisms of disease: protease functions in intestinal mucosal pathobiology. Nat Clin Pract Gastroenterol Hepatol 2007, 4:393-402.

88. Hewitson JP, Grainger JR, Maizels RM: Helminth immunoregulation: the role of parasite secreted proteins in modulating host immunity. $\mathrm{Mol}$ Biochem Parasitol 2009, 167:1-11.

89. Redmond DL, Smith SK, Halliday A, Smith WD, Jackson F, Knox DP, Matthews JB: An immunogenic cathepsin F secreted by the parasitic stages of Teladorsagia circumcincta. Int J Parasitol 2006, 36:277-286.

90. The National Center for Biotechnology Information Library browser: Ovis aries. [http://www.ncbi.nlm.nih.gov/UniGene/lbrowse2.cgi?TAXID=9940].

91. Simpson HV: Pathophysiology of abomasal parasitism: is the host or parasite responsible? Vet J 2000, 160:177-191.
92. Knight PA, Pemberton AD, Robertson KA, Roy DJ, Wright SH, Miller HR: Expression profiling reveals novel innate and inflammatory responses in the jejunal epithelial compartment during infection with Trichinella spiralis. Infect Immun 2004, 72:6076-6086.

doi:10.1186/1297-9716-42-78

Cite this article as: Knight et al:: Novel gene expression responses in the ovine abomasal mucosa to infection with the gastric nematode Teladorsagia circumcincta. Veterinary Research 2011 42:78.

\section{Submit your next manuscript to BioMed Central and take full advantage of:}

- Convenient online submission

- Thorough peer review

- No space constraints or color figure charges

- Immediate publication on acceptance

- Inclusion in PubMed, CAS, Scopus and Google Scholar

- Research which is freely available for redistribution

Submit your manuscript at www.biomedcentral.com/submit
C Biomed Central 